\title{
2,3-dihydrochromeno[3,4-d]imidazol-4(1H)-one derivatives as
} potent anticancer cell proliferation and migration agents

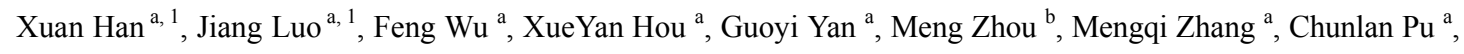 \\ Rui Li ${ }^{\text {a, * }}$ \\ ${ }^{a}$ National Key Laboratory of Biotherapy and Cancer Center, West China Hospital, Sichuan University, and \\ Collaborative Innovation Center for Biotherapy, Chengdu, 610041 Sichuan, P. R. China \\ ${ }^{b}$ Engineering Research Center for the Development and Application of Ethnic Medicine and TCM (Ministry of \\ Educa-tion), School of Pharmacy, Guiyang Medical University, 9 Beijing Road, Guiyang, Guizhou, 550004, P. R. \\ China.
}

\begin{abstract}
In this study, a series of novel molecules containing chromeno [3,4-d] imidazol-4(1H)-one was synthesized and their biological activities were evaluated. Among them, compound 35 showed a dramatic anticancer activity against HCT116 and MCF-7, and the flow cytometry assays demonstrated that it could arrest G0/G1 cell-cycle and induce apoptosis of SW620 cells in a dose-dependent manner. Besides, it also blocked MCF-7 cancer cell migration. Moreover, it inhibited tumor growth in HCT116 subcutaneously implanted xenografted mice. Taken together, compound $\mathbf{3 5}$ may be a promising candidate for anti-cancer agent as well as metastatic one.
\end{abstract}

Keywords: chromeno [3,4-d] imidazol-4(1H)-one; anti-cancer agents, anti-metastasis

\section{Introduction}

Cancer is becoming a leading cause of death in developing and developed countries. An estimated 14.1 million new cancer cases occurred in 2012 worldwide and Eastern Asia accounted for $29.4 \%$ of it [1]. There were 8.2 million cancer deaths in 2012 all over the world, and cancer has also been the first reason of death in China under the age of $65[1,2]$.

A pharmacophore hybrid approach for exploration of novel and highly active compounds is an effective and commonly used direction in modern medicinal chemistry. Hybridization of two different bioactive molecules with complementary pharmacophoric functions often showed synergistic effects [3, 4]. For instance, pyrazole [5] and stilbene [6] conjugated with coumarin derivatives possess good antiproliferative activities. Given the important role of this fusion strategy, previously, we also synthesized a series of triazol and coumarin fused derivatives which showed efficient anticancer activities [7].

The coumarin and its derivatives are widely used for antitumor agents [8-11]. The structural modification and structure-activity relationship analysis of coumarins on anticancer effect have 
been fueled by various academics and industries [12-14]. Another prevalent scaffold, imidazole template, is a privileged structure fragment in current medicinal chemistry [15-21]. In particular, benzimidazole and imidazoquinoline derivatives are well known for their pharmaceutical properties, which have been extended to widespread inhibitors of proton pump [22], hypertension, virus [23] and cancer [24-26]. (Fig. 1.) Because there are few reports on the biological research on the coumarin and imidazole fused skeleton, in this study, a series of compounds possessing a chromeno [3,4-d] imidazol-4(1H)-one core was synthesized and their structure-activity relationships (SAR) were studied.

\section{Results and discussion}

\subsection{Structure and activity relationship}

At the beginning of our research, the coumarin analogues were substituted by the simple phenyl on the N-1 position and aryl fragments on $\mathrm{C}-6$ position. As displayed in Table 1, phenyl groups including pyridin-3-yl, 3- $\mathrm{NH}_{2}-\mathrm{C}_{6} \mathrm{H}_{4}, 2-\mathrm{Me}_{-} \mathrm{C}_{6} \mathrm{H}_{4}, 4-\mathrm{OH}-\mathrm{C}_{6} \mathrm{H}_{4}$ and $3-\mathrm{NHSO}_{2}-\left(4-\mathrm{F}-\mathrm{C}_{6} \mathrm{H}_{4}\right)-\mathrm{C}_{6} \mathrm{H}_{4}$ on the C-6 position showed no bioactivity. When the pyridin-4-yl and quinolin-3-yl substituted the C-6 position of coumarin, the inhibitory activities of compounds $\mathbf{1 5}$ and $\mathbf{1 6}$ against three tested cancer cell lines were improved.

Furthermore, we turned our attention to the phenyl ring at the N-1 position. Compounds 17 - 25 with $4-\mathrm{CH}_{2} \mathrm{CN}$ in the phenyl ring displayed slight improvement in inhibitory activities against U87-MG, PC-3 and HCT116 cancer cell lines. Specifically, when $3-\mathrm{NH}_{2}-\mathrm{C}_{6} \mathrm{H}_{4}$ was introduced to the C-6 position, compound 19 showed moderate activity against $\mathrm{PC}-3$ cell line with $\mathrm{IC}_{50}$ value of $36.51 \mu \mathrm{M}$. Furthermore, compound 21 that containing a 4-OH- $\mathrm{C}_{6} \mathrm{H}_{4}$, exhibited some bioactivity with value of $29.37 \mu \mathrm{M}$. Besides, pyridine-3-yl (22) or quinolin-3-yl (25) at C-6 position showed better activities with $\mathrm{IC}_{50}$ values of $29.37 \mu \mathrm{M}$ and $28.4 \mu \mathrm{M}$ against HCT116 cells, indicating that the nitrogen atom on the heterocyclic substitute is crucial to the bioactivity, which may provide a hydrogen acceptor site.

To further investigate the SAR of N-1 group, with pyridin-4-yl, pyridine-3-yl or quinolin-3-yl retained at C6-position, the phenyl was replaced by $4-\mathrm{OMe}-\mathrm{C}_{6} \mathrm{H}_{4}$ and $2-\mathrm{Me}-\mathrm{C}_{6} \mathrm{H}_{4}$. However, all the compounds (compounds 26 to 31) showed no bioactivity, suggesting that the cyano of 4- $\mathrm{CH}_{2} \mathrm{CN}-\mathrm{C}_{6} \mathrm{H}_{4}$ group is a very crucial moiety which may provide a hydrogen acceptor site. When N4- $\mathrm{C}\left(\mathrm{CH}_{3}\right)_{2}-\mathrm{C}_{6} \mathrm{H}_{4}$ group was introduced to the N-1 position, all compounds showed an improved inhibitory activities. Compound 32 with pyridin-3-yl at C-6 position showed antitumor activity against U87-MG cells with $\mathrm{IC}_{50}$ value of $25.62 \mu \mathrm{M}$ and 33 inhibited U87-MG and PC-3 with $\mathrm{IC}_{50}$ values of $28.55 \mu \mathrm{M}$ and $29.01 \mu \mathrm{M}$, respectively. What's more, $\mathbf{3 4}$ with quinolin-3-yl displayed higher bioactivity against the U87-MG, PC-3 and HCT116 cell lines with $\mathrm{IC}_{50}$ values of 33.42 , 19.76, $20.40 \mu \mathrm{M}$.

Out of our expectation, when a methyl group was attempted to introduce to N-3 position, tert-butoxy was accidentally inserted into $\mathrm{C}-2$ of imidazole ring. To our delight, compound $\mathbf{3 5}$ possesses attractive antitumor activity against $\mathrm{HCT} 116$ with $\mathrm{IC}_{50}$ value of $1.40 \mu \mathrm{M}, 15$ fold stronger than that of $\mathbf{3 4}$. (Table 2) It can be concluded that the good inhibitory activity does not simply reside in the quinolin-3-yl at C-6 position, but also the methyl and tert-butoxy at the ring of imidazole. 


\subsection{Biological evaluation}

\subsubsection{Compound 35 inhibited many kinds of cancer cells with low toxicity to normal LO2 cells}

In order to investigate whether $\mathbf{3 5}$ has widely anti-cancer activities, the proliferation inhibition on colon carcinoma SW420 cell, CT26 cell and HCT116 cell, human breast carcinoma MCF-7 cell and lung carcinoma A549 cell were tested. As a result, compound 35 displayed attractive antitumor activities against SW620, CT26, HCT116, MCF-7, and A549 with $\mathrm{IC}_{50}$ values of 3.55, 3.50, 1.40, 1.70 and $9.50 \mu \mathrm{M}$, respectively (Fig. 2A). Meanwhile, it also expressed relatively low cytotoxicity to $\mathrm{LO} 2$ normal cell with the $\mathrm{IC}_{50}$ value of $37.0 \mu \mathrm{M}$.

\subsubsection{Compound 35 inhibited the formation of colony in HCT116}

As indicated in Fig. 2B, after the treatment of 35, the size of the colonies was apparently smaller than that of the non-treated group. When the concentration of 35 was increased to $2.50 \mu \mathrm{M}$, nearly no colony formation was observed.

\subsubsection{Compound 35 induced $G 0 / G 1$ phase arrest and apoptosis}

The effects of $\mathbf{3 5}$ on SW620 cell cycle distribution were shown in Fig. 3A. Under the treatment of 35, SW620 cells were arrested significantly at the G0/G1 phase compared to the untreated group, with the percentage of G0/G1 increased from $38.47 \%$ (control) to $38.78 \%(0.3125 \mu \mathrm{M})$, $40.30 \%(0.625 \mu \mathrm{M}), 42.97 \%(1.25 \mu \mathrm{M}), 47.49 \%(2.50 \mu \mathrm{M})$ and $60.04 \%(5.0 \mu \mathrm{M})$, respectively. Meanwhile, the number of cells in S and G2/M phase decreased. Furthermore, flow cytometry analysis using Annexin V-FITC and propidium iodide (PI) staining showed that $\mathbf{3 5}$ treatment at $0.3125,0.625,1.25,2.50$ and $5.0 \mu \mathrm{M}$ increased the percentage of apoptosis cells from $2.83 \%$ to $15.71 \%, 25.19 \%, 26.22 \%$ and $42.90 \%$, respectively. From the above experiments, it can be concluded that 35 could induce G0/G1 arrest and apoptosis of SW620 cells in a dose-dependent manner.

\subsubsection{Compound 35 blocked MCF-7 cancer cell migration}

To further test the effect of $\mathbf{3 5}$ on the cancer cell migration potential, wound healing assay was conducted on MCF-7 cells. As shown in Fig. 4, after treatment with 35 at $5.0 \mu \mathrm{M}$ for 24 h, the breast cancer cell migration was suppressed obviously.

\subsubsection{Compound 35 inhibited tumor growth in HCT116 mouse mammary tumor model}

To assess the antitumor effect of $\mathbf{3 5}$ in vivo, nude mice were administered $\mathbf{3 5}$ by subcutaneous injection at the dose of $40 \mathrm{mg} / \mathrm{kg}$ and $80 \mathrm{mg} / \mathrm{kg}$. As shown in Fig. 5A, 35 Amarkedly suppressed tumor growth in a dose-dependent manner with the inhibition of tumor progression at $52.96 \%$ in the $80 \mathrm{mg} / \mathrm{kg}$ group. In addition, $\mathbf{3 5}$ treatment was well tolerated and did not cause significant body weight loss (Fig. 5B).

\section{Conclusion}

In this research, a series of chromeno [3,4-d] imidazol-4(1H)-one derivatives was synthesized and their antitumor activities in vitro against U87-MG cells, PC-3 cells and HCT116 cells were 
tested. Among these compounds, 35 exhibits excellent broad spectrum anticancer activities in vitro with $\mathrm{IC}_{50}$ values of $1.40 \mu \mathrm{M}, 3.55 \mu \mathrm{M}, 1.70 \mu \mathrm{M}, 3.50 \mu \mathrm{M}$ and $9.50 \mu \mathrm{M}$ against HCT116, SW620, MCF-7, CT26 and A549 respectively. In addition, structure activity relationship research reveals that $4-\mathrm{C}\left(\mathrm{CH}_{3}\right)_{2}-\mathrm{CN}-\mathrm{C}_{6} \mathrm{H}_{4}$ at N-1 position of coumarin core is the best optimal for bioactivity; a methyl group at N-3 position and tert-butoxy inserted into C-2 of imidazole are indispensable for the improvement of potency; the quinolin-3-yl at C-6 position of coumarin core can make a positive contribution to the activity. Flow cytometry experiment demonstrates that compound $\mathbf{3 5}$ can arrest the cell cycle of SW620 at G0/G1 and induce apoptosis in a concentration-dependent manner. Further in vivo anticancer experiments on subcutaneous HCT116 tumor model in nude mice show that 35 can inhibit tumor growth by $52.96 \%$ at $80 \mathrm{mg} / \mathrm{kg} / 48 \mathrm{~h}$ for 20 days. Altogether, our results provide a novel scaffold with better potency as antitumor agents. All the results encourage us to continue the development and the further validation of mechanism at the molecular level.

\section{Experimental section}

\subsection{General methods for chemistry}

All the reagents and solvents were purchased from commercial vendors and dried by standard methods in advance and distilled before used. ${ }^{1} \mathrm{H}$ and ${ }^{13} \mathrm{C}$ NMR spectra were recorded on with a Bruker AC-E400 spectrometer (operating at $400 \mathrm{MHz}$ ), with chemical shift in parts per million (ppm, $\delta$ ) downfield from TMS as an internal standard. Mass spectrometry (MS) data were obtained using a BrukerAmjzon spectrometer. Compound purity was determined by a Waters 1525 series HPLC system with a confirming purity $\underline{\mathrm{\theta}} \mathrm{f} 95 \%$ for all of the final biologically tested compounds. Flash column chromatography was completed by silica gel.

3-(4,5)-dimethylthiahiazo(-z-y1)-3,5-di-phenytetrazoliumromide (MTT), DMSO, DMEM, were from Sigma. The Annexin V-FITC Apoptosis Detection Kit was purchased from KeyGEN BioTECH.

\subsection{General procedure for the synthesis of $\mathbf{1}-\mathbf{5}$}

\subsubsection{Synthesis of 1}

The mixture of 4-bromophenol $(116 \mathrm{mmol})$ and acetic anhydride $(464 \mathrm{mmol})$ in pyridine $(60$ $\mathrm{mL}$ ) was stirred at $100{ }^{\circ} \mathrm{C}$ for $3.5 \mathrm{~h}$. Then the reaction mixture was cooled to room temperature and quenched with water. The reaction was acidized with hydrochloric acid and extracted with ethyl acetate $(40 \mathrm{~mL} \times 3)$. The combined organic layer was washed by saturated sodium chloride solution for three times, dried over anhydrous $\mathrm{Na}_{2} \mathrm{SO}_{4}$ and concentrated under reduced pressure. The residue was purified by silica gel chromatography. 1: yield 100\%.

\subsubsection{Synthesis of 2}

A suspension of 1 (46 mmol) and aluminum chloride $(69 \mathrm{mmol})$ was stirred at $150{ }^{\circ} \mathrm{C}$. After $3.5 \mathrm{~h}$ the mixture was cooled to room temperature and the diluted hydrochloric acid was added to it slowly for quenching aluminum chloride until all solid disappeared. Then the solution was extracted with ethyl acetate $(20 \mathrm{~mL} \times 3)$, and the combined organic layer was washed by saturated 
sodium chloride solution for three times, dried over anhydrous $\mathrm{Na}_{2} \mathrm{SO}_{4}$ and concentrated under reduced pressure. The decolorized solid was recrystallized with n-hexane. 2: yield $72 \% .{ }^{1} \mathrm{H}$ NMR $\left(400 \mathrm{MHz}, \mathrm{CDCl}_{3}\right): \delta 7.38(\mathrm{~d}, J=8.0 \mathrm{~Hz}, 1 \mathrm{H}), 7.32(\mathrm{~s}, 1 \mathrm{H}), 7.23$ (d, $\left.J=7.9 \mathrm{~Hz}, 1 \mathrm{H}\right), 7.06$ (d, $J=$ $8.2 \mathrm{~Hz}, 1 \mathrm{H}), 2.28(\mathrm{~s}, 3 \mathrm{H}) \mathrm{ppm}$.

\subsubsection{Synthesis of 3}

$2(74 \mathrm{mmol})$ and diethyl carbonate $(111 \mathrm{mmol})$ in toluene $(160 \mathrm{~mL})$ were added dropwise to sodium hydride $(369 \mathrm{mmol})$ in toluene $(50 \mathrm{~mL})$ in ice-water bath. The mixture was stirred at ice bath for $30 \mathrm{~min}$ and at $100{ }^{\circ} \mathrm{C}$ for $4 \mathrm{~h}$. The sodium hydride was quenched with water, acidized with hydrochloric acid and then the suspension was filtered separately, and the solid collected from this filtration was washed with toluene and water for three times. The solid dried at room temperature with phosphorus pentoxide. 3: yield 71\%. ${ }^{1} \mathrm{H}$ NMR $\left(400 \mathrm{MHz}, \mathrm{CDCl}_{3}\right): \delta 12.17$ (s, $1 \mathrm{H}), 7.83(\mathrm{~d}, J=2.45,1 \mathrm{H}), 7.55(\mathrm{dd}, J=2.4 \mathrm{~Hz}, 8.8 \mathrm{~Hz}, 1 \mathrm{H}), 6.90(\mathrm{~d}, J=9.2 \mathrm{~Hz}, 1 \mathrm{H}), 2.63(\mathrm{~s}, 3 \mathrm{H})$ ppm.

\subsubsection{Synthesis of 4}

6-bromo-4-hydroxy-2H-chromen-2-one $(0.15 \mathrm{~mol})$ was dissolved in dichloromethane $(300 \mathrm{~mL})$ and then stirred at room temperature. The solution was acidified with hydrochloric acid and the yellow solid was filtered off and subsequently washed with water and acetic acid. 4: yield 94\%. ESI-MS: Calcd for $\mathrm{C}_{9} \mathrm{H}_{4} \mathrm{BrNO}_{5}$ [M-H]: 463.98, Found 284.93, 286.93, found 283.9, 285.9. ${ }^{1} \mathrm{H}$ NMR (400 MHz, d6-DMSO): $\delta 7.93(\mathrm{~d}, J=2.4 \mathrm{~Hz}, 1 \mathrm{H}), 7.68$ (dd, $J=2.4 \mathrm{~Hz}, 8.8 \mathrm{~Hz}, 1 \mathrm{H}), 7.84$ $(\mathrm{d}, J=8.8 \mathrm{~Hz}, 1 \mathrm{H}) \mathrm{ppm}$.

\subsubsection{Synthesis of 5}

To a suspension of 6-bromo-4-hydroxy-3-nitro-2H-chromen-2-one $(10 \mathrm{mmol})$ in phosphorus oxychloride $(15 \mathrm{~mL})$ was added triethylamine slowly. The mixture was stirred and refluxed for $1 \mathrm{~h}$. The phosphorus oxychloride was quenched with water carefully, then the suspension was filtered and the decolorized solid was recrystallized with ethyl acetate and petroleum ether. 5: yield $87 \%$. ${ }^{1} \mathrm{H}$ NMR (400 MHz, d6-DMSO): $\delta 7.92(\mathrm{~d}, J=2.4 \mathrm{~Hz}, 1 \mathrm{H}), 7.67(\mathrm{dd}, J=2.6 \mathrm{~Hz}, 9.0 \mathrm{~Hz}, 1 \mathrm{H}$ ), $7.18(\mathrm{~d}, J=8.8 \mathrm{~Hz}, 1 \mathrm{H}) \mathrm{ppm}$.

\subsection{General procedure for the synthesis of $\mathbf{6 a}-\boldsymbol{6} \boldsymbol{e}$}

A mixture of corresponding phenylamine $(20 \mathrm{mmol})$ and $5(20 \mathrm{mmol})$ was added into DMF (50 $\mathrm{mL}$ ). The reaction mixture was stirred at room temperature for $5 \mathrm{~h}$. Then, it was diluted with water and the separated solid was filtered off, washed with water, ethanol and ethyl acetate.

\subsubsection{6-bromo-3-nitro-4-(phenylamino)-2H-chromen-2-one (6a)}

Yield: 95\%. ESI-MS: Calcd for $\mathrm{C}_{15} \mathrm{H}_{9} \mathrm{BrN}_{2} \mathrm{O}_{4}[\mathrm{M}-\mathrm{H}]=$ : 358.97, 360.98, Found 358.9, 360.9. ${ }^{1} \mathrm{H}$ NMR (400 MHz, DMSO) $\delta 10.36(\mathrm{~s}, 1 \mathrm{H}), 8.35(\mathrm{~d}, J=8.7 \mathrm{~Hz}, 1 \mathrm{H}), 7.84(\mathrm{~d}, J=1.7 \mathrm{~Hz}, 1 \mathrm{H}), 7.74$ (dd, $J=8.7,1.7 \mathrm{~Hz}, 1 \mathrm{H}), 7.37$ (t, $J=7.7 \mathrm{~Hz}, 2 \mathrm{H}), 7.25(\mathrm{t}, J=7.4 \mathrm{~Hz}, 1 \mathrm{H}), 7.20(\mathrm{~d}, J=7.7 \mathrm{~Hz}, 2 \mathrm{H})$ ppm. 


\subsubsection{2-(4-((6-bromo-3-nitro-2-oxo-2H-chromen-4-yl)amino)phenyl)acetonitrile (6b)}

Yield: 93\%. ESI-MS: Calcd for $\mathrm{C}_{17} \mathrm{H}_{10} \mathrm{BrN}_{3} \mathrm{O}_{4}[\mathrm{M}+\mathrm{Na}]^{+}:$421.99, 423.99, Found 422.0, 423.7. ${ }^{1} \mathrm{H}$ NMR (400 MHz, DMSO): $\delta 10.37$ (s, 1H), $8.74(\mathrm{~s}, 1 \mathrm{H}), 7.96(\mathrm{~d}, J=7.2 \mathrm{~Hz}, 1 \mathrm{H}), 7.47$ (d, $J=$ $8.8 \mathrm{~Hz}, 1 \mathrm{H}), 7.35(\mathrm{~d}, J=8.4 \mathrm{~Hz}, 2 \mathrm{H}), 7.23(\mathrm{~d}, J=8.4 \mathrm{~Hz}, 2 \mathrm{H}), 4.08(\mathrm{~s}, 2 \mathrm{H}) \mathrm{ppm}$.

\subsubsection{6-bromo-4-((4-methoxyphenyl)amino)-3-nitro-2H-chromen-2-one (6c)}

Yield: 95\%. ESI-MS: Calcd for $\mathrm{C}_{16} \mathrm{H}_{11} \mathrm{BrN}_{2} \mathrm{O}_{5}[\mathrm{M}-\mathrm{H}]^{-}:$388.99, 390.98, Found 389.0, 391.1. ${ }^{1} \mathrm{H}$ NMR (400 MHz, DMSO): $\delta 10.25(\mathrm{~s}, 1 \mathrm{H}), 8.33(\mathrm{~d}, J=8.8 \mathrm{~Hz}, 1 \mathrm{H}), 7.82(\mathrm{~d}, J=1.8 \mathrm{~Hz}, 1 \mathrm{H}), 7.73$ $(\mathrm{dd}, J=8.7,1.8 \mathrm{~Hz}, 1 \mathrm{H}), 7.15(\mathrm{~d}, J=8.9 \mathrm{~Hz}, 2 \mathrm{H}), 6.92$ (d, $J=8.9 \mathrm{~Hz}, 2 \mathrm{H}), 3.77$ (s, 3H) ppm.

\subsubsection{6-bromo-3-nitro-4-(o-tolylamino)-2H-chromen-2-one (6d)}

Yield: 97\%. ESI-MS: Calcd for $\mathrm{C}_{16} \mathrm{H}_{11} \mathrm{BrN}_{2} \mathrm{O}_{4}[\mathrm{M}+\mathrm{Na}]^{+}$: 396.99, 398.99, Found 397.2, 399.2. ${ }^{1} \mathrm{H}$ NMR $\left(400 \mathrm{MHz}, \mathrm{CDCl}_{3}\right) \delta 11.43(\mathrm{~s}, 1 \mathrm{H}), 7.63(\mathrm{~d}, J=8.8 \mathrm{~Hz}, 1 \mathrm{H}), 7.42(\mathrm{~m}, 2 \mathrm{H}), 7.32(\mathrm{t}, J=$ $6.7 \mathrm{~Hz}, 1 \mathrm{H}), 7.20(\mathrm{~m}, 2 \mathrm{H}), 7.14(\mathrm{~d}, J=7.8 \mathrm{~Hz}, 1 \mathrm{H}), 2.36(\mathrm{~s}, 3 \mathrm{H}) \mathrm{ppm}$.

\subsubsection{2-(4-((6-bromo-3-nitro-2-oxo-2H-chromen-4-yl)amino)phenyl)-2-methylpropanenitrile (6e)}

Yield: 95\%. ESI-MS: Calcd for $\mathrm{C}_{19} \mathrm{H}_{14} \mathrm{BrN}_{3} \mathrm{O}_{4}[\mathrm{M}-\mathrm{H}]^{-}:$426.02, 429.01, Found 426.1, 428.1. ${ }^{1} \mathrm{H}$ NMR (400 MHz, DMSO) $\delta 10.37$ (s, 1H), 8.33 (d, $J=8.9 \mathrm{~Hz}, 1 \mathrm{H}), 7.85$ (d, $J=1.8 \mathrm{~Hz}, 1 \mathrm{H}), 7.75$ $(\mathrm{dd}, J=8.7,1.7 \mathrm{~Hz}, 1 \mathrm{H}), 7.51(\mathrm{~d}, J=8.6 \mathrm{~Hz}, 2 \mathrm{H}), 7.25(\mathrm{~d}, J=8.5 \mathrm{~Hz}, 2 \mathrm{H}), 1.69$ (s, 6H) ppm.

\subsection{General procedure for the synthesis of $7 \boldsymbol{a}-7 \boldsymbol{e}$}

A $250 \mathrm{~mL}$ 3-necked round-bottom flask was charged with a solution of iron (166.2 mmol) and $\mathrm{NH}_{4} \mathrm{Cl}(50 \mathrm{mmol})$ in $3: 1$ ethanol: water $(70 \mathrm{~mL})$, heated to $100{ }^{\circ} \mathrm{C}$, charged with $6(6 \mathrm{~g}, 16.62$ mmol) in several batches and stirred for $5 \mathrm{~h}$. The reaction mixture was cooled, and added into a solution of $\mathrm{Na}_{2} \mathrm{CO}_{3}$. The separated solid was filtered off and extracted with ethyl acetate. The combined organic layers were dried over sodium sulfate, filtered and concentrated in vacuo.

\subsubsection{3-amino-6-bromo-4-(phenylamino)-2H-chromen-2-one (7a)}

Yield: 59\%. ESI-MS: Calcd for $\mathrm{C}_{15} \mathrm{H}_{11} \mathrm{BrN}_{2} \mathrm{O}_{2}[\mathrm{M}+\mathrm{H}]^{+}: 331.00,333.00$, Found 330.6, 332.7. ${ }^{1} \mathrm{H}$ NMR (400 MHz, $\left.\mathrm{CDCl}_{3}\right): \delta 7.57(\mathrm{~d}, J=1.6 \mathrm{~Hz}, 1 \mathrm{H}), 7.41(\mathrm{dd}, J=2.0,8.8 \mathrm{~Hz}, 1 \mathrm{H}), 7.29(\mathrm{~m}, 2 \mathrm{H})$, $7.22(\mathrm{~d}, J=8.4 \mathrm{~Hz}, 1 \mathrm{H}), 6.94(\mathrm{t}, J=14.4,7.2 \mathrm{~Hz}, 1 \mathrm{H}), 7.21(\mathrm{~d}, J=8.0 \mathrm{~Hz}, 2 \mathrm{H}), 5.50(\mathrm{~s}, 1 \mathrm{H}), 4.13$ (br, 2H) ppm.

\subsubsection{2-(4-((3-amino-6-bromo-2-oxo-2H-chromen-4-yl)amino)phenyl)acetonitrile (7b)}

Yield: $63 \%$. ESI-MS: Calcd for $\mathrm{C}_{17} \mathrm{H}_{12} \mathrm{BrN}_{3} \mathrm{O}_{2}[\mathrm{M}+\mathrm{Na}]^{+}$: 392.01, 394.01, Found 389.9, 391.9. ${ }^{1} \mathrm{H}$ NMR (400 MHz, $\left.\mathrm{CDCl}_{3}\right): \delta 7.53(\mathrm{~d}, J=2.4 \mathrm{~Hz}, 1 \mathrm{H}), 7.43(\mathrm{dd}, J=8.8,2.4 \mathrm{~Hz}, 1 \mathrm{H}), 7.22(\mathrm{~m}$, 4H), 6.71 (d, $J=8.4 \mathrm{~Hz}, 1 \mathrm{H}), 5.44$ (s, 1H), 4.13 (br, 2H), 3.75 (s, 2H) ppm.

\subsubsection{3-amino-6-bromo-4-((4-methoxyphenyl)amino)-2H-chromen-2-one (7c)}

Yield: 54\%. ESI-MS: Calcd for $\mathrm{C}_{16} \mathrm{H}_{13} \mathrm{BrN}_{2} \mathrm{O}_{3}[\mathrm{M}+\mathrm{H}]^{+}:$361.01, 363.01, Found 360.6, 363.7. ${ }^{1} \mathrm{H}$ NMR (400 MHz, $\left.\mathrm{CDCl}_{3}\right): \delta 7.55(\mathrm{~s}, 1 \mathrm{H}), 7.42(\mathrm{~d}, J=8.8 \mathrm{~Hz}, 1 \mathrm{H}), 7.23(\mathrm{~d}, J=8.6 \mathrm{~Hz}, 1 \mathrm{H}), 6.86$ $(\mathrm{d}, J=8.1 \mathrm{~Hz}, 2 \mathrm{H}), 6.73(\mathrm{~d}, J=8.2 \mathrm{~Hz}, 2 \mathrm{H}), 5.41(\mathrm{~s}, 1 \mathrm{H}), 3.79(\mathrm{~s}, 3 \mathrm{H}), 1.26(\mathrm{~s}, 2 \mathrm{H}) \mathrm{ppm}$. 
4.4.4 3-amino-6-bromo-4-(o-tolylamino)-2H-chromen-2-one (7d)

Yield: 52\%. ESI-MS: Calcd for C16H13BrN2O2 [M+ K] $]^{+}: 383.02,385.01$, Found 383.2, 384.5. ${ }^{1} \mathrm{H}$ NMR (400 MHz, DMSO) $\delta 7.95(\mathrm{~s}, 1 \mathrm{H}), 7.42(\mathrm{dd}, J=8.7,1.6 \mathrm{~Hz}, 1 \mathrm{H}), 7.32(\mathrm{~d}, J=7.7 \mathrm{~Hz}$, 2H), $7.17(\mathrm{~d}, J=7.3 \mathrm{~Hz}, 1 \mathrm{H}), 6.95(\mathrm{t}, J=7.5 \mathrm{~Hz}, 1 \mathrm{H}), 6.89(\mathrm{~s}, 1 \mathrm{H}), 6.78(\mathrm{t}, J=7.3 \mathrm{~Hz}, 1 \mathrm{H}), 6.31$ $(\mathrm{d}, J=7.9 \mathrm{~Hz}, 1 \mathrm{H}), 5.27(\mathrm{~s}, 1 \mathrm{H}), 2.37(\mathrm{~s}, 3 \mathrm{H}) \mathrm{ppm}$.

4.4.5 2-(4-((3-amino-6-bromo-2-oxo-2H-chromen-4-yl)amino)phenyl)-2-methylpropanenitrile (7e) Yield: 61\%. ESI-MS: Calcd for $\mathrm{C}_{19} \mathrm{H}_{16} \mathrm{BrN}_{3} \mathrm{O}_{2}[\mathrm{M}+\mathrm{Na}]^{+}:$420.04.02, 422.04, Found 420.2, 422.5. ${ }^{1} \mathrm{H}$ NMR (400 MHz, d $\mathrm{d}^{6}$-DMSO): $\delta 7.96$ (s, 1H), 7.55 (d, $\left.J=2.0 \mathrm{~Hz}, 1 \mathrm{H}\right), 7.45$ (dd, $J=1.8$ $\mathrm{Hz}, 8.6 \mathrm{~Hz}, 1 \mathrm{H}), 7.35$ (s, 1H), 7.32 (d, $J=9.2 \mathrm{~Hz}, 2 \mathrm{H}), 6.67$ (d, $J=8.8 \mathrm{~Hz}, 2 \mathrm{H}), 5.24$ (s, 2H), 1.63 (s, 6H) ppm.

\subsection{General procedure for the synthesis of $\mathbf{8 a}-\mathbf{8 e}$}

Compound 7 (9 mmol) and 1, 1'-carbonyldiimidazole (45 $\mathrm{mmol})$ in acetic acid (50 $\mathrm{mL})$ were stirred for $12 \mathrm{~h}$ at $120^{\circ} \mathrm{C}$. The reaction mixture was cooled and concentrated in vacuo to remove most of the acetic acid. The residual solution was added into water. The precipitate was filtered and extracted with ethyl acetate and then it was purified by silica gel chromatography.

\subsubsection{8-bromo-1-phenyl-1,3-dihydrochromeno[3,4-d]imidazole-2,4-dione (8a)}

Yield: $74 \%$. ESI-MS: Calcd for $\mathrm{C}_{16} \mathrm{H}_{9} \mathrm{BrN}_{2} \mathrm{O}_{3}[\mathrm{M}+\mathrm{H}]^{+}: 356.98,358.98$, Found 355.1, 357.1. ${ }^{1} \mathrm{H}$ NMR (400 MHz, d $\left.{ }^{6}-\mathrm{DMSO}\right): \delta 12.12(\mathrm{~s}, 1 \mathrm{H}), 7.68$ (d, $\left.J=3.2 \mathrm{~Hz}, 3 \mathrm{H}\right), 7.61(\mathrm{~m}, 3 \mathrm{H}), 7.46(\mathrm{~d}, J=$ $8.8 \mathrm{~Hz}, 1 \mathrm{H}), 6.62(\mathrm{~d}, J=2.0 \mathrm{~Hz}, 1 \mathrm{H}) \mathrm{ppm}$.

4.5.2 2-(4-(8-bromo-2,4-dioxo-2,3-dihydrochromeno[3,4-d]imidazol-1(4H)-yl)phenyl)acetonitrile (8b)

Yield: 70\%. ESI-MS: Calcd for $\mathrm{C}_{18} \mathrm{H}_{10} \mathrm{BrN}_{3} \mathrm{O}_{3}[\mathrm{M}+\mathrm{H}]^{+}:$395.99, 397.99 Found 393.9, 395.9. ${ }^{1} \mathrm{H}$ NMR (400 MHz, d - DMSO): $\delta 7.76(\mathrm{~s}, 4 \mathrm{H}), 7.65(\mathrm{~m}, 1 \mathrm{H}), 7.50(\mathrm{~d}, J=8.8 \mathrm{~Hz}, 1 \mathrm{H}), 6.62(\mathrm{~d}, J=$ $2.0 \mathrm{~Hz}, 1 \mathrm{H}), 4.30(\mathrm{~s}, 2 \mathrm{H}) \mathrm{ppm}$

\subsubsection{8-bromo-1-(4-methoxyphenyl)-1,3-dihydrochromeno[3,4-d]imidazole-2,4-dione (8c)}

Yield: 45\%. ESI-MS: Calcd for $\mathrm{C}_{17} \mathrm{H}_{11} \mathrm{BrN}_{2} \mathrm{O}_{4}[\mathrm{M}+\mathrm{H}]^{+}: 386.99,388.99$ Found 385.0, 387.0. ${ }^{1} \mathrm{H}$ NMR (400 MHz, d6-DMSO): $\delta 7.62$ (m, 3H), 7.47 (d, J=8.9 Hz, 1H), 7.29 (d, J=8.7 Hz, 2H), $6.67(\mathrm{~d}, J=2.0 \mathrm{~Hz}, 1 \mathrm{H}), 3.92(\mathrm{~s}, 3 \mathrm{H}) \mathrm{ppm}$. ESI-MS: 385, $387[\mathrm{M}+\mathrm{H}]^{+}$.

\subsubsection{8-bromo-1-(o-tolyl)-1,3-dihydrochromeno[3,4-d]imidazole-2,4-dione (8d)}

Yield: $62 \%$. ESI-MS: Calcd for $\mathrm{C}_{17} \mathrm{H}_{11} \mathrm{BrN}_{2} \mathrm{O}_{3}[\mathrm{M}+\mathrm{H}]^{+}: 370.00,371.99$ Found 369.1, 371.1. ${ }^{1} \mathrm{H}$ NMR (400 MHz, d $-\mathrm{DMSO}): \delta 7.65(\mathrm{~m}, 5 \mathrm{H}), 7.49(\mathrm{~d}, J=8.8 \mathrm{~Hz}, 1 \mathrm{H}), 6.45(\mathrm{~d}, J=1.4 \mathrm{~Hz}, 1 \mathrm{H})$, 1.98 (s, 3H) ppm.

\subsection{5}

2-(4-(8-bromo-2,4-dioxo-2,3-dihydrochromeno[3,4-d]imidazol-1(4H)-yl)phenyl)-2-methylpropane nitrile $(\mathbf{8 e})$

Yield: 56\%. ESI-MS: Calcd for $\mathrm{C}_{20} \mathrm{H}_{14} \mathrm{BrN}_{3} \mathrm{O}_{3}[\mathrm{M}+\mathrm{Na}]^{+}:$446.02, 448.02 Found 444.3, 446.3. 
${ }^{1} \mathrm{H}$ NMR (400 MHz, d ${ }^{6}$-DMSO): 87.93 (d, $\left.J=8.8 \mathrm{~Hz}, 2 \mathrm{H}\right), 7.81(\mathrm{~d}, J=8.4 \mathrm{~Hz}, 2 \mathrm{H}), 7.63$ (dd, $J=$ $2.0 \mathrm{~Hz}, 8.8 \mathrm{~Hz}, 1 \mathrm{H}), 7.49$ (d, $J=8.8 \mathrm{~Hz}, 1 \mathrm{H}), 6.41(\mathrm{~d}, J=2.4 \mathrm{~Hz}, 1 \mathrm{H}), 1.83(\mathrm{~s}, 6 \mathrm{H}) \mathrm{ppm}$.

4.6 General procedure for the synthesis of 9-35

A mixture of $8(0.1 \mathrm{mmol})$, boric acid $(0.11 \mathrm{mmol}), \mathrm{PdCl}_{2}(\mathrm{dppf}) \mathrm{CH}_{2} \mathrm{Cl}_{2}(0.05 \mathrm{mmol})$ and $\mathrm{K}_{2} \mathrm{CO}_{3}(0.3 \mathrm{mmol})$ in dioxane/water $(3 / 1 \mathrm{~mL})$ was bubbled with nitrogen for 10 minutes, and heated in a sealed tube at $50{ }^{\circ} \mathrm{C}$ for $5 \mathrm{~h}$. After cooling the reaction mixture was partitioned with water. The aqueous layer was further extracted with ethyl acetate. The organic extract was washed with brine, dried over sodium sulfate, and it was purified by silica gel chromatography.

\subsubsection{1,8-diphenyl-1,3-dihydrochromeno[3,4-d] imidazole-2,4-dione (9)}

Yield: 44\%. ESI-MS: Calcd for $\mathrm{C}_{22} \mathrm{H}_{14} \mathrm{~N}_{2} \mathrm{O}_{3}[\mathrm{M}+\mathrm{H}]^{+}: 355.10$ Found 353.2. ${ }^{1} \mathrm{H}$ NMR (400 MHz, $\left.\mathrm{CDCl}_{3}\right) \delta 7.71(\mathrm{~s}, 3 \mathrm{H}), 7.61(\mathrm{~d}, J=8.6 \mathrm{~Hz}, 1 \mathrm{H}), 7.49(\mathrm{~d}, J=8.4 \mathrm{~Hz}, 3 \mathrm{H}), 7.32(\mathrm{~m}, 3 \mathrm{H}), 7.19(\mathrm{~d}, J$ $=7.2 \mathrm{~Hz}, 2 \mathrm{H}), 6.84(\mathrm{~s}, 1 \mathrm{H}) \mathrm{ppm}$.

\subsubsection{1-phenyl-8-(pyridin-3-yl)-1,3-dihydrochromeno[3,4-d] imidazole-2,4-dione (10)}

Yield: 43\%. ESI-MS: Calcd for $\mathrm{C}_{21} \mathrm{H}_{13} \mathrm{~N}_{3} \mathrm{O}_{3}[\mathrm{M}+\mathrm{Na}]^{+}$: 378.10 Found 376.0. ${ }^{1} \mathrm{H}$ NMR (400 $\left.\mathrm{MHz} \mathrm{CDCl}_{3}\right) \delta 8.54(\mathrm{~d}, J=3.7 \mathrm{~Hz}, 1 \mathrm{H}), 8.41(\mathrm{~d}, J=1.8 \mathrm{~Hz}, 1 \mathrm{H}), 7.73(\mathrm{dt}, \mathrm{J}=4.2 \mathrm{~Hz}, 5.4 \mathrm{~Hz}, 3 \mathrm{H}$, $3 \mathrm{H}), 7.60(\mathrm{dd}, J=8.6,2.1 \mathrm{~Hz}, 1 \mathrm{H}), 7.55(\mathrm{~m}, 2 \mathrm{H}), 7.49(\mathrm{dd}, J=7.7,1.7 \mathrm{~Hz}, 2 \mathrm{H}), 7.29(\mathrm{dd}, J=8.0$, $4.9 \mathrm{~Hz}, 1 \mathrm{H}), 6.82(\mathrm{~d}, J=2.0 \mathrm{~Hz}, 1 \mathrm{H}) \mathrm{ppm}$.

\subsubsection{8-(3-aminophenyl)-1-phenyl-1,3-dihydrochromeno[3,4-d]imidazole-2,4-dione (11)}

Yield: 57\%. ESI-MS: Calcd for $\mathrm{C}_{22} \mathrm{H}_{15} \mathrm{~N}_{3} \mathrm{O}_{3}[\mathrm{M}+\mathrm{H}]^{+}:$370.11 Found 368.3. ${ }^{1} \mathrm{H}$ NMR (400 MHz, DMSO) $\delta 7.76(\mathrm{~d}, J=5.7 \mathrm{~Hz}, 5 \mathrm{H}), 7.62(\mathrm{~d}, J=8.6 \mathrm{~Hz}, 1 \mathrm{H}), 7.54(\mathrm{~d}, J=8.6 \mathrm{~Hz}, 1 \mathrm{H}), 6.97$ (t, $J=$ $7.7 \mathrm{~Hz}, 1 \mathrm{H}), 6.72(\mathrm{~s}, 1 \mathrm{H}), 6.50(\mathrm{~d}, J=8.0 \mathrm{~Hz}, 1 \mathrm{H}), 6.47(\mathrm{~s}, 1 \mathrm{H}), 6.28(\mathrm{~d}, J=7.5 \mathrm{~Hz}, 1 \mathrm{H}), 5.11(\mathrm{~s}$, 2H) ppm.

\subsubsection{1-phenyl-8-(o-tolyl)-1,3-dihydrochromeno[3,4-d]imidazole-2,4-dione (12)}

Yield: 55\%. ESI-MS: Calcd for $\mathrm{C}_{23} \mathrm{H}_{16} \mathrm{~N}_{2} \mathrm{O}_{3}[\mathrm{M}+\mathrm{Na}]^{+}$: 391.12 Found 389.0. ${ }^{1} \mathrm{H}$ NMR (400 $\left.\mathrm{MHz} \mathrm{CDCl}_{3}\right) \delta 7.62(\mathrm{~s}, 3 \mathrm{H}), 7.49(\mathrm{~d}, J=8.6 \mathrm{~Hz}, 1 \mathrm{H}), 7.43(\mathrm{~s}, 2 \mathrm{H}), 7.35(\mathrm{~d}, J=8.6 \mathrm{~Hz}, 1 \mathrm{H}), 7.18$ $(\mathrm{m}, 3 \mathrm{H}), 7.00(\mathrm{~d}, J=7.2 \mathrm{~Hz}, 1 \mathrm{H}), 6.66(\mathrm{~s}, 1 \mathrm{H}), 2.38(\mathrm{~s}, 3 \mathrm{H}) \mathrm{ppm}$.

\subsubsection{8-(4-hydroxyphenyl)-1-phenyl-1,3-dihydrochromeno[3,4-d]imidazole-2,4-dione (13)}

Yield: 52\%. ESI-MS: Calcd for $\mathrm{C}_{22} \mathrm{H}_{14} \mathrm{~N}_{2} \mathrm{O}_{4}[\mathrm{M}-\mathrm{H}]^{-}: 369.10$ Found 367.1. ${ }^{1} \mathrm{H}$ NMR (400 MHz, DMSO) $\delta 9.59(\mathrm{~s}, 1 \mathrm{H}), 7.75(\mathrm{~d}, \mathrm{~J}=3.1 \mathrm{~Hz}, 5 \mathrm{H}), 7.65(\mathrm{dd}, J=8.7,2.2 \mathrm{~Hz}, 1 \mathrm{H}), 7.50(\mathrm{~d}, J=8.7 \mathrm{~Hz}$, $1 \mathrm{H}), 7.01(\mathrm{~d}, J=8.6 \mathrm{~Hz}, 2 \mathrm{H}), 6.71(\mathrm{~d}, J=8.6 \mathrm{~Hz}, 2 \mathrm{H}), 6.65(\mathrm{~d}, J=2.0 \mathrm{~Hz}, 1 \mathrm{H}) \mathrm{ppm}$.

4.6.6

N-(3-(2,4-dioxo-1-phenyl-1,2,3,4-tetrahydrochromeno[3,4-d]imidazol-8-yl)phenyl)-4-fluorobenzen esulfonamide (14)

Yield: 56\%. ESI-MS: Calcd for $\mathrm{C}_{28} \mathrm{H}_{18} \mathrm{FN}_{3} \mathrm{O}_{5} \mathrm{~S}$ [M- H] ${ }^{-}$: 526.10 Found 524.3. ${ }^{1} \mathrm{H}$ NMR (400 MHz, DMSO) $\delta 10.40(\mathrm{~s}, 1 \mathrm{H}), 7.81(\mathrm{~m}, 2 \mathrm{H}), 7.74(\mathrm{~s}, 5 \mathrm{H}), 7.58(\mathrm{~s}, 2 \mathrm{H}), 7.40(\mathrm{t}, J=8.3 \mathrm{~Hz}, 2 \mathrm{H})$, $7.22(\mathrm{t}, J=7.8 \mathrm{~Hz}, 1 \mathrm{H}), 7.10(\mathrm{~s}, 1 \mathrm{H}), 7.00(\mathrm{~d}, J=8.0 \mathrm{~Hz}, 1 \mathrm{H}), 6.80(\mathrm{~d}, J=7.7 \mathrm{~Hz}, 1 \mathrm{H}), 6.71(\mathrm{~s}$, 
1H) ppm.

4.6.7 1-phenyl-8-(pyridin-4-yl)-1,3-dihydrochromeno[3,4-d]imidazole-2,4-dione (15)

Yield: 57\%. ESI-MS: Calcd for $\mathrm{C}_{21} \mathrm{H}_{13} \mathrm{~N}_{3} \mathrm{O}_{3}[\mathrm{M}+\mathrm{H}]^{+}:$356.10 Found 354.0. ${ }^{1} \mathrm{H}$ NMR (400 MHz, $\left.\mathrm{CDCl}_{3}\right) \delta 8.57(\mathrm{~d}, \mathrm{~J}=4.8 \mathrm{~Hz}, 2 \mathrm{H}), 7.74(\mathrm{~m}, 3 \mathrm{H}), 7.66(\mathrm{dd}, J=8.7,1.9 \mathrm{~Hz}, 1 \mathrm{H}), 7.52(\mathrm{~m}, 3 \mathrm{H}), 7.09$ (d, $J=5.4 \mathrm{~Hz}, 2 \mathrm{H}), 6.87(\mathrm{~s}, 1 \mathrm{H}) \mathrm{ppm}$.

4.6.8 1-phenyl-8-(quinolin-3-yl)-1,3-dihydrochromeno[3,4-d]imidazole-2,4-dione (16)

Yield: 40\%. ESI-MS: Calcd for $\mathrm{C}_{25} \mathrm{H}_{15} \mathrm{~N}_{3} \mathrm{O}_{3}[\mathrm{M}+\mathrm{Na}]^{+}:$428.11 Found 426.1. ${ }^{1} \mathrm{H}$ NMR (400 $\left.\mathrm{MHz} \mathrm{CDCl}_{3}\right) \delta 8.72(\mathrm{~d}, J=2.2 \mathrm{~Hz}, 1 \mathrm{H}), 8.11(\mathrm{~d}, J=8.4 \mathrm{~Hz}, 1 \mathrm{H}), 8.00(\mathrm{~d}, J=1.9 \mathrm{~Hz}, 1 \mathrm{H}), 7.75$ $(\mathrm{m}, 6 \mathrm{H}), 7.59(\mathrm{t}, J=8.0 \mathrm{~Hz}, 2 \mathrm{H}), 7.52(\mathrm{~m}, 2 \mathrm{H}), 6.94(\mathrm{~d}, J=2.0 \mathrm{~Hz}, 1 \mathrm{H}) \mathrm{ppm}$.

\subsection{9}

2-(4-(2,4-dioxo-8-(o-tolyl)-2,3-dihydrochromeno[3,4-d]imidazol-1(4H)-yl)phenyl)acetonitrile (17)

Yield: 52\%. ESI-MS: Calcd for $\mathrm{C}_{25} \mathrm{H}_{17} \mathrm{~N}_{3} \mathrm{O}_{3}$ [M- H] : 406.13 Found 404.2. ${ }^{1} \mathrm{H}$ NMR (400 MHz, $\left.\mathrm{CDCl}_{3}\right) \delta 7.63(\mathrm{~d}, J=8.1 \mathrm{~Hz}, 2 \mathrm{H}), 7.49(\mathrm{dd}, J=8.2,6.0 \mathrm{~Hz}, 3 \mathrm{H}), 7.37(\mathrm{dd}, J=8.6,2.0 \mathrm{~Hz}, 1 \mathrm{H})$, 7.19 (m, 3H), 7.00 (d, $J=7.1 \mathrm{~Hz}, 1 \mathrm{H}), 6.65$ (d, $J=1.9 \mathrm{~Hz}, 1 \mathrm{H}), 3.88$ (s, 2H), 2.37 (s, 3H) ppm.

4.6.10

N-(3-(1-(4-(cyanomethyl)phenyl)-2,4-dioxo-1,2,3,4-tetrahydrochromeno[3,4-d]imidazol-8-yl)phen yl)-4-fluorobenzenesulfonamide (18)

Yield: 43\%. ESI-MS: Calcd for $\mathrm{C}_{30} \mathrm{H}_{19} \mathrm{FN}_{4} \mathrm{O}_{5} \mathrm{~S}$ [M- H] : 565.11 Found 563.2. ${ }^{1} \mathrm{H}$ NMR (400 MHz, DMSO) $\delta 10.43(\mathrm{~s}, 1 \mathrm{H}), 7.78(\mathrm{~m}, 6 \mathrm{H}), 7.61(\mathrm{~s}, 2 \mathrm{H}), 7.39(\mathrm{t}, J=8.8 \mathrm{~Hz}, 2 \mathrm{H}), 7.25(\mathrm{t}, J=7.9$ $\mathrm{Hz}, 1 \mathrm{H}), 7.16(\mathrm{~s}, 1 \mathrm{H}), 6.94(\mathrm{~d}, J=8.1 \mathrm{~Hz}, 1 \mathrm{H}), 6.79$ (d, $J=7.9 \mathrm{~Hz}, 1 \mathrm{H}), 6.74(\mathrm{~s}, 1 \mathrm{H}), 4.25(\mathrm{~s}, 2 \mathrm{H})$ ppm.

\subsubsection{1}

2-(4-(8-(3-aminophenyl)-2,4-dioxo-2,3-dihydrochromeno[3,4-d] imidazol-1(4H)-yl)phenyl)acetonit rile (19)

Yield: 55\%. ESI-MS: Calcd for $\mathrm{C}_{24} \mathrm{H}_{16} \mathrm{~N}_{4} \mathrm{O}_{3}[\mathrm{M}+\mathrm{H}]^{+}:$409.12 Found 407.3. ${ }^{1} \mathrm{H}$ NMR (400 MHz, $\left.\mathrm{CDCl}_{3}\right) \delta 7.72(\mathrm{~d}, J=7.9 \mathrm{~Hz}, 2 \mathrm{H}), 7.56(\mathrm{dd}, J=15.8,8.9 \mathrm{~Hz}, 3 \mathrm{H}), 7.46(\mathrm{~d}, J=8.6 \mathrm{~Hz}, 1 \mathrm{H}), 7.15(\mathrm{t}$, $J=7.8 \mathrm{~Hz}, 1 \mathrm{H}), 6.76(\mathrm{~s}, 1 \mathrm{H}), 6.63(\mathrm{~d}, J=8.5 \mathrm{~Hz}, 1 \mathrm{H}), 6.57(\mathrm{~d}, J=7.5 \mathrm{~Hz}, 1 \mathrm{H}), 6.50(\mathrm{~s}, 1 \mathrm{H}), 3.96$ $(\mathrm{s}, 2 \mathrm{H}), 3.79(\mathrm{~s}, 2 \mathrm{H}) \mathrm{ppm}$.

\subsubsection{2}

2-(4-(2,4-dioxo-8-phenyl-2,3-dihydrochromeno[3,4-d] imidazol-1(4H)-yl)phenyl)acetonitrile (20)

Yield: 55\%. ESI-MS: Calcd for $\mathrm{C}_{24} \mathrm{H}_{15} \mathrm{~N}_{3} \mathrm{O}_{3}$ [M- H] ${ }^{-}$: 392.11 Found 390.2. ${ }^{1} \mathrm{H}$ NMR (400 MHz, $\left.\mathrm{CDCl}_{3}\right) \delta 7.72(\mathrm{~d}, J=8.2 \mathrm{~Hz}, 2 \mathrm{H}), 7.62(\mathrm{dd}, J=8.7,2.1 \mathrm{~Hz}, 1 \mathrm{H}), 7.56(\mathrm{~d}, J=8.2 \mathrm{~Hz}, 2 \mathrm{H}), 7.50(\mathrm{~d}$, $J=8.6 \mathrm{~Hz}, 1 \mathrm{H}), 7.39$ (t, $J=7.4 \mathrm{~Hz}, 2 \mathrm{H}), 7.32(\mathrm{t}, J=7.3 \mathrm{~Hz}, 1 \mathrm{H}), 7.20(\mathrm{~d}, J=7.2 \mathrm{~Hz}, 2 \mathrm{H}), 6.79(\mathrm{~d}$, $J=2.0 \mathrm{~Hz}, 1 \mathrm{H}), 3.95(\mathrm{~s}, 2 \mathrm{H}) \mathrm{ppm}$.

4.6 .13

2-(4-(8-(4-hydroxyphenyl)-2,4-dioxo-2,3-dihydrochromeno[3,4-d]imidazol-1(4H)-yl)phenyl)aceto nitrile (21) 
401

402

403

404

405

406

407

408

409

410

411

412

413

414

415

416

417

418

419

420

421

422

423

424

425

426

427

428

429

430

431

432

433

434

Yield: 55\%. ESI-MS: Calcd for $\mathrm{C}_{24} \mathrm{H}_{15} \mathrm{~N}_{3} \mathrm{O}_{4}[\mathrm{M}-\mathrm{H}]=$ : 308.11 Found 306.2. ${ }^{1} \mathrm{H}$ NMR (400 MHz, $\mathrm{d}^{6}$-DMSO): $\delta 9.64(\mathrm{~s}, 1 \mathrm{H}), 7.79(\mathrm{~m}, 4 \mathrm{H}), 7.70(\mathrm{dd}, J=2.0 \mathrm{~Hz}, 8.8 \mathrm{~Hz}, 1 \mathrm{H}), 7.52$ (d, $J=8.8 \mathrm{~Hz}$, $1 \mathrm{H}), 7.05(\mathrm{~d}, J=8.8 \mathrm{~Hz}, 2 \mathrm{H}), 6.79(\mathrm{~d}, J=8.4 \mathrm{~Hz}, 2 \mathrm{H}), 6.67(\mathrm{~d}, J=2.0 \mathrm{~Hz}, 1 \mathrm{H}), 4.30$ (s, 2H) ppm.

4.6.14

2-(4-(2,4-dioxo-8-(pyridin-3-yl)-2,3-dihydrochromeno[3,4-d]imidazol-1(4H)-yl)phenyl)acetonitril e (22)

Yield: 51\%. ESI-MS: Calcd for $\mathrm{C}_{23} \mathrm{H}_{14} \mathrm{~N}_{4} \mathrm{O}_{3}[\mathrm{M}+\mathrm{H}]^{+}:$395.11 Found 393.1. ${ }^{1} \mathrm{H}$ NMR (400 MHz, $\left.\mathrm{CDCl}_{3}\right): \delta 8.55(\mathrm{~s}, 1 \mathrm{H}), 8.45(\mathrm{~s}, 1 \mathrm{H}), 7.23(\mathrm{~d}, J=8.4 \mathrm{~Hz}, 2 \mathrm{H}), 7.59(\mathrm{~d}, J=8.4 \mathrm{~Hz}, 3 \mathrm{H}), 7.51(\mathrm{t}, J=$ $9.6 \mathrm{~Hz}, 2 \mathrm{H}), 7.35(\mathrm{~m}, 1 \mathrm{H}), 6.78(\mathrm{~d}, J=1.6 \mathrm{~Hz}, 1 \mathrm{H}), 3.99(\mathrm{~s}, 2 \mathrm{H}) \mathrm{ppm}$.

4.6.15

2-(4-(8-(4-(methylsulfonyl)phenyl)-2,4-dioxo-2,3-dihydrochromeno[3,4-d]imidazol-1(4H)-yl)phen yl)acetonitrile (23)

Yield: 49\%. ESI-MS: Calcd for $\mathrm{C}_{25} \mathrm{H}_{17} \mathrm{~N}_{3} \mathrm{O}_{5} \mathrm{~S}[\mathrm{M}+\mathrm{H}]^{+}: 472.09$ Found 470.2. ${ }^{1} \mathrm{H}$ NMR (400 $\left.\mathrm{MHz} \mathrm{CDCl}_{3}\right) \delta 7.96(\mathrm{~d}, J=8.2 \mathrm{~Hz}, 2 \mathrm{H}), 7.73(\mathrm{~d}, J=7.7 \mathrm{~Hz}, 2 \mathrm{H}), 7.64(\mathrm{~d}, J=7.3 \mathrm{~Hz}, 1 \mathrm{H}), 7.56$ (m, 3H), 7.37 (d, $J=8.2 \mathrm{~Hz}, 2 \mathrm{H}), 6.80(\mathrm{~s}, 1 \mathrm{H}), 3.96$ (s, 2H), 3.08 (s, 3H) ppm.

4.6.16

2-(4-(2,4-dioxo-8-(pyridin-4-yl)-2,3-dihydrochromeno[3,4-d]imidazol-1(4H)-yl)phenyl)acetonitril e (24)

Yield: 58\%. ESI-MS: Calcd for $\mathrm{C}_{23} \mathrm{H}_{14} \mathrm{~N}_{4} \mathrm{O}_{3}[\mathrm{M}+\mathrm{H}]^{+}$: 395.11 Found 393.0. ${ }^{1} \mathrm{H}$ NMR (400 MHz, $\left.\mathrm{CDCl}_{3}\right) \delta 8.62(\mathrm{~s}, 2 \mathrm{H}), 7.74(\mathrm{~d}, J=8.2 \mathrm{~Hz}, 2 \mathrm{H}), 7.67(\mathrm{dd}, J=8.6,2.1 \mathrm{~Hz}, 1 \mathrm{H}), 7.56(\mathrm{~d}, J=7.6 \mathrm{~Hz}$, $3 \mathrm{H}), 7.11(\mathrm{~d}, J=2.8 \mathrm{~Hz}, 2 \mathrm{H}), 6.84(\mathrm{~d}, J=2.0 \mathrm{~Hz}, 1 \mathrm{H}), 3.97$ (s, 2H) ppm.

4.6.17

2-(4-(2,4-dioxo-8-(quinolin-3-yl)-2,3-dihydrochromeno[3,4-d]imidazol-1(4H)-yl)phenyl)acetonitri le (25)

Yield: 52\%. ESI-MS: Calcd for $\mathrm{C}_{27} \mathrm{H}_{16} \mathrm{~N}_{4} \mathrm{O}_{3}[\mathrm{M}+\mathrm{H}]^{+}:$445.12 Found 443.3. ${ }^{1} \mathrm{H}$ NMR (400 MHz, $\left.\mathrm{CDCl}_{3}\right): \delta 8.72(\mathrm{~s}, 1 \mathrm{H}), 8.10(\mathrm{~d}, J=8.4 \mathrm{~Hz}, 1 \mathrm{H}), 8.01(\mathrm{~s}, 1 \mathrm{H}), 7.84(\mathrm{~d}, J=8.0 \mathrm{~Hz}, 1 \mathrm{H}), 7.75(\mathrm{~m}$, 4H), 7.60 (m, 4H), 7.27 (s, 1H), 6.92 (s, 1H), 3.99 (s, 2H) ppm.

4.6.18 1-(4-methoxyphenyl)-8-(pyridin-3-yl)-1,3-dihydrochromeno[3,4-d]imidazole-2,4-dione (26)

Yield: 47\%. ESI-MS: Calcd for $\mathrm{C}_{22} \mathrm{H}_{15} \mathrm{~N}_{3} \mathrm{O}_{4}[\mathrm{M}+\mathrm{H}]^{+}:$386.11 Found 384.0. ${ }^{1} \mathrm{H}$ NMR (400 MHz, $\left.\mathrm{CDCl}_{3}\right) \delta 8.56(\mathrm{~d}, J=4.2 \mathrm{~Hz}, 1 \mathrm{H}), 8.50(\mathrm{~s}, 1 \mathrm{H}), 7.56(\mathrm{~m}, 3 \mathrm{H}), 7.39(\mathrm{~d}, J=8.6 \mathrm{~Hz}, 2 \mathrm{H}), 7.30(\mathrm{~m}$, 1H), $7.18(\mathrm{~d}, J=8.6 \mathrm{~Hz}, 2 \mathrm{H}), 6.92(\mathrm{~s}, 1 \mathrm{H}), 3.96(\mathrm{~d}, J=7.8 \mathrm{~Hz}, 3 \mathrm{H}) \mathrm{ppm}$.

4.6.19 1-(4-methoxyphenyl)-8-(pyridin-4-yl)-1,3-dihydrochromeno[3,4-d]imidazole-2,4-dione (27)

Yield: 43\%. ESI-MS: Calcd for $\mathrm{C}_{22} \mathrm{H}_{15} \mathrm{~N}_{3} \mathrm{O}_{4}[\mathrm{M}+\mathrm{H}]^{+}:$386.11 Found 384.0. ${ }^{1} \mathrm{H}$ NMR (400 MHz, $\left.\mathrm{CDCl}_{3}\right) \delta 8.59(\mathrm{~s}, 2 \mathrm{H}), 7.66(\mathrm{~d}, J=8.2 \mathrm{~Hz}, 1 \mathrm{H}), 7.54(\mathrm{~d}, J=8.6 \mathrm{~Hz}, 1 \mathrm{H}), 7.40(\mathrm{~d}, J=8.4 \mathrm{~Hz}, 2 \mathrm{H})$, $7.19(\mathrm{~m}, 4 \mathrm{H}), 6.94(\mathrm{~s}, 1 \mathrm{H}), 3.97$ (s, 3H) ppm.

4.6.20 1-(4-methoxyphenyl)-8-(quinolin-3-yl)-1,3-dihydrochromeno[3,4-d]imidazole-2,4-dione (28) 
Yield: 53\%. ESI-MS: Calcd for $\mathrm{C}_{26} \mathrm{H}_{17} \mathrm{~N}_{3} \mathrm{O}_{4}[\mathrm{M}+\mathrm{H}]^{+}$: 436.12 Found 334.1. ${ }^{1} \mathrm{H}$ NMR (400 MHz, $\left.\mathrm{CDCl}_{3}\right) \delta 8.85(\mathrm{~s}, 2 \mathrm{H}), 7.79(\mathrm{~m}, 4 \mathrm{H}), 7.60(\mathrm{~d}, J=8.1 \mathrm{~Hz}, 1 \mathrm{H}), 7.42(\mathrm{~d}, J=7.9 \mathrm{~Hz}, 3 \mathrm{H}), 7.22(\mathrm{~d}, J$ $=7.0 \mathrm{~Hz}, 2 \mathrm{H}), 7.03(\mathrm{~s}, 1 \mathrm{H}), 3.97(\mathrm{~s}, 3 \mathrm{H}) \mathrm{ppm}$.

4.6.21 8-(quinolin-3-yl)-1-(o-tolyl)-1,3-dihydrochromeno[3,4-d]imidazole-2,4-dione (29)

Yield: 55\%. ESI-MS: Calcd for $\mathrm{C}_{26} \mathrm{H}_{17} \mathrm{~N}_{3} \mathrm{O}_{3}[\mathrm{M}+\mathrm{H}]^{+}: 420.13$ Found 418.2. ${ }^{1} \mathrm{H}$ NMR (400 MHz, $\left.\mathrm{CDCl}_{3}\right) \delta 8.65(\mathrm{~s}, 1 \mathrm{H}), 8.05(\mathrm{~d}, J=8.2 \mathrm{~Hz}, 1 \mathrm{H}), 7.92(\mathrm{~s}, 1 \mathrm{H}), 7.73(\mathrm{~d}, J=8.0 \mathrm{~Hz}, 1 \mathrm{H}), 7.66(\mathrm{~m}$, 3H), 7.59 (d, $J=7.3 \mathrm{~Hz}, 1 \mathrm{H}), 7.49$ (m, 3H), 7.36 (d, J=7.6 Hz, 1H), $6.76(\mathrm{~s}, 1 \mathrm{H}), 2.01(\mathrm{~s}, 3 \mathrm{H})$ ppm.

\subsubsection{8-(pyridin-3-yl)-1-(o-tolyl)-1,3-dihydrochromeno[3,4-d]imidazole-2,4-dione (30)}

Yield: $51 \%$. ESI-MS: Calcd for $\mathrm{C}_{22} \mathrm{H}_{15} \mathrm{~N}_{3} \mathrm{O}_{3}[\mathrm{M}+\mathrm{H}]^{+}:$370.11 Found 368.3. ${ }^{1} \mathrm{H}$ NMR (400 MHz, $\left.\mathrm{CDCl}_{3}\right) \delta 8.48(\mathrm{~s}, 1 \mathrm{H}), 8.34(\mathrm{~s}, 1 \mathrm{H}), 7.51(\mathrm{~m}, 6 \mathrm{H}), 7.33(\mathrm{~d}, J=7.7 \mathrm{~Hz}, 1 \mathrm{H}), 7.22(\mathrm{~s}, 1 \mathrm{H}), 6.65(\mathrm{~d}, J$ $=1.4 \mathrm{~Hz}, 1 \mathrm{H}), 1.98(\mathrm{~d}, J=5.8 \mathrm{~Hz}, 3 \mathrm{H}) \mathrm{ppm}$.

\subsubsection{8-(pyridin-4-yl)-1-(o-tolyl)-1,3-dihydrochromeno[3,4-d]imidazole-2,4-dione (31)}

Yield: $46 \%$. ESI-MS: Calcd for $\mathrm{C}_{22} \mathrm{H}_{15} \mathrm{~N}_{3} \mathrm{O}_{3}[\mathrm{M}+\mathrm{H}]^{+}:$370.11 Found 368.3. ${ }^{1} \mathrm{H}$ NMR (400 MHz, $\left.\mathrm{CDCl}_{3}\right) \delta 8.57(\mathrm{~s}, 2 \mathrm{H}), 7.66(\mathrm{dd}, J=11.3,4.3 \mathrm{~Hz}, 2 \mathrm{H}), 7.56(\mathrm{dd}, J=12.8,7.7 \mathrm{~Hz}, 3 \mathrm{H}), 7.42(\mathrm{~d}, J=$ $7.6 \mathrm{~Hz}, 1 \mathrm{H}), 7.08(\mathrm{~d}, J=4.2 \mathrm{~Hz}, 2 \mathrm{H}), 6.77(\mathrm{~d}, J=1.8 \mathrm{~Hz}, 1 \mathrm{H}), 2.06(\mathrm{~s}, 3 \mathrm{H}) \mathrm{ppm}$.

\section{6 .24}

2-(4-(2,4-dioxo-8-(pyridin-3-yl)-2,3-dihydrochromeno[3,4-d]imidazol-1(4H)-yl)phenyl)-2-methylp ropanenitrile (32)

Yield: $60 \%$. ESI-MS: Calcd for $\mathrm{C}_{25} \mathrm{H}_{18} \mathrm{~N}_{4} \mathrm{O}_{3}[\mathrm{M}+\mathrm{Na}]^{+}: 445.14$ Found 443.1. ${ }^{1} \mathrm{H}$ NMR (400 $\left.\mathrm{MHz} \mathrm{CDCl}_{3}\right) \delta 8.54(\mathrm{~s}, 1 \mathrm{H}), 8.43(\mathrm{~s}, 1 \mathrm{H}), 7.85(\mathrm{~d}, J=8.1 \mathrm{~Hz}, 2 \mathrm{H}), 7.55(\mathrm{~m}, 4 \mathrm{H}), 7.28(\mathrm{~s}, 2 \mathrm{H})$, $6.69(\mathrm{~s}, 1 \mathrm{H}), 1.87(\mathrm{~s}, 6 \mathrm{H}) \mathrm{ppm}$. 4.6.25 2-(4-(2,4-dioxo-8-(pyridin-4-yl)-2,3-dihydrochromeno[3,4-d]imidazol-1(4H)-yl)phenyl)-2-methylp ropanenitrile (33)

Yield: 56\%. ESI-MS: Calcd for $\mathrm{C}_{25} \mathrm{H}_{18} \mathrm{~N}_{4} \mathrm{O}_{3}[\mathrm{M}+\mathrm{Na}]^{+}$: 445.14 Found 443.1. ${ }^{1} \mathrm{H}$ NMR (400 $\left.\mathrm{MHz}, \mathrm{CDCl}_{3}\right) \delta 8.56(\mathrm{~d}, J=4.8 \mathrm{~Hz}, 2 \mathrm{H}), 7.87(\mathrm{~d}, J=8.2 \mathrm{~Hz}, 2 \mathrm{H}), 7.67(\mathrm{~m}, 2 \mathrm{H}), 7.56(\mathrm{t}, J=8.5$ $\mathrm{Hz}, 3 \mathrm{H}), 7.08$ (d, J=4.5 Hz, 2H), 6.78 (s, 1H), 1.88 (s, 6H) ppm.

4.6.26

2-(4-(2,4-dioxo-8-(quinolin-3-yl)-2,3-dihydrochromeno[3,4-d]imidazol-1(4H)-yl)phenyl)-2-methyl propanenitrile (34)

Yield: 48\%. ESI-MS: Calcd for $\mathrm{C}_{29} \mathrm{H}_{20} \mathrm{~N}_{4} \mathrm{O}_{3}[\mathrm{M}+\mathrm{Na}]^{+}$: 495.15 Found 493.2. ${ }^{1} \mathrm{H}$ NMR (400 MHz, d $\left.\mathrm{d}^{6}-\mathrm{DMSO}\right): \delta 8.71(\mathrm{~d}, J=2.0 \mathrm{~Hz}, 1 \mathrm{H}), 8.28(\mathrm{~s}, 1 \mathrm{H}), 7.98(\mathrm{~m}, 5 \mathrm{H}), 7.86(\mathrm{~d}, J=8.4 \mathrm{~Hz}, 2 \mathrm{H})$, $7.78(\mathrm{t}, J=7.8 \mathrm{~Hz}, 1 \mathrm{H}), 7.71(\mathrm{~d}, J=8.4 \mathrm{~Hz}, 1 \mathrm{H}), 7.65(\mathrm{t}, J=7.4 \mathrm{~Hz}, 1 \mathrm{H}), 6.82(\mathrm{~d}, J=1.6 \mathrm{~Hz}, 1 \mathrm{H})$, $2.65(\mathrm{~s}, 6 \mathrm{H}) \mathrm{ppm}$.

\subsection{Procedure for the synthesis of $35 a$}

A mixture of compound $8 \mathrm{e}(1 \mathrm{mmol}), \mathrm{CH}_{3} \mathrm{I}(1 \mathrm{mmol})$, and potassium tert-butanolate $(3 \mathrm{mmol})$ in DMF was stirred at $0{ }^{\circ} \mathrm{C}$ for 20 minutes. The reaction mixture was partitioned with water. Then 
the aqueous layer was further extracted with ethyl acetate. The organic extract was washed with brine, dried over sodium sulfate, and it was purified by silica gel chromatography. 2-(4-(8-bromo-2-(tert-butoxy)-2,3-dimethyl-4-oxo-2,3-dihydrochromeno[3,4-d]imidazol-1(4H)-yl) phenyl)-2-methylpropanenitrile (35a)

Yield: 7\%. ESI-MS: Calcd for $\mathrm{C}_{26} \mathrm{H}_{28} \mathrm{BrN}_{3} \mathrm{O}_{3}[\mathrm{M}+\mathrm{H}]^{+}:$510.13, 512.13 Found 510.2, $512.2{ }^{1} \mathrm{H}$ NMR (400 MHz, DMSO): $\delta 7.55$ (d, $J=8.3 \mathrm{~Hz}, 2 \mathrm{H}), 7.44(\mathrm{dd}, J=8.8,2.3 \mathrm{~Hz}, 1 \mathrm{H}), 7.37(\mathrm{~d}, J=$ $2.3 \mathrm{~Hz}, 1 \mathrm{H}), 7.29(\mathrm{~d}, J=8.2 \mathrm{~Hz}, 2 \mathrm{H}), 6.84(\mathrm{~d}, J=8.9 \mathrm{~Hz}, 1 \mathrm{H}), 3.49$ (s, 3H), 2.18 (s, 3H), 1.66 (s, $6 \mathrm{H}), 1.23$ (s, 9H) ppm. ESI-MS: 510.2, $512.2[\mathrm{M}+\mathrm{H}]^{+}$.

\subsection{1}

2-(4-(2-(tert-butoxy)-2,3-dimethyl-4-oxo-8-(quinolin-3-yl)-2,3-dihydrochromeno[3,4-d]imidazol-1 (4H)-yl)phenyl)-2-methylpropanenitrile (35)

Yield: 55\%. ESI-MS: Calcd for $\mathrm{C}_{35} \mathrm{H}_{34} \mathrm{~N}_{4} \mathrm{O}_{3}[\mathrm{M}+\mathrm{H}]^{+}:$559.26 Found 559.3. ${ }^{1} \mathrm{H}$ NMR (400 MHz, $\left.\mathrm{CDCl}_{3}\right): \delta 9.03(\mathrm{~s}, 1 \mathrm{H}), 8.16(\mathrm{~s}, 1 \mathrm{H}), 8.11(\mathrm{~d}, J=8.4 \mathrm{~Hz}, 1 \mathrm{H}), 7.84(\mathrm{~d}, J=8.1 \mathrm{~Hz}, 1 \mathrm{H}), 7.71(\mathrm{t}, J=$ $7.6 \mathrm{~Hz}, 1 \mathrm{H}), 7.64(\mathrm{~d}, J=8.5 \mathrm{~Hz}, 1 \mathrm{H}), 7.57(\mathrm{t}, J=7.5 \mathrm{~Hz}, 1 \mathrm{H}), 7.52(\mathrm{~s}, 1 \mathrm{H}), 7.46(\mathrm{~d}, J=8.2 \mathrm{~Hz}$, 2H), $7.16(\mathrm{~d}, J=8.1 \mathrm{~Hz}, 2 \mathrm{H}), 6.90$ (d, $J=8.6 \mathrm{~Hz}, 1 \mathrm{H}), 3.64(\mathrm{~s}, 3 \mathrm{H}), 2.36(\mathrm{~s}, 3 \mathrm{H}), 1.68(\mathrm{~s}, 6 \mathrm{H})$, 1.36 (s, 9H) ppm. ${ }^{13} \mathrm{C}$ NMR (400 MHz, DMSO): $\delta 161.71,157.12,149.03,146.46,144.82,131.86$, $131.62,131.21,130.16,129.23,128.86,128.61,128.33,128.17,127.90,127.67,127.01,125.93$, $124.27,119.72,111.69,78.85,55.40,36.45,28.05,27.60,13.64 \mathrm{ppm} . \mathrm{Mp}=205-207{ }^{\circ} \mathrm{C}$.

\subsection{Biological evaluation}

\subsubsection{Cell Culture and reagents preparation}

Mouse colorectal carcinoma CT26 cell, human colorectal carcinoma HCT116 and SW620 cells, human breast carcinoma MCF-7 cell, lung carcinoma A549 cell and human hepatocytes LO2 cell were obtained from the American Type Culture Collection (ATCC, Rockville, MD, USA). Cells were propagated in DMEM or RPMI 1350 media containing 10\% fetal bovine serum (FBS; Gibco, Auckland, N. Z.) and $1 \%$ antibiotics (penicillin and streptomycin) in $5 \% \mathrm{CO}_{2}$ at $37{ }^{\circ} \mathrm{C}$.

\subsubsection{MTT Assay}

The cell viability was performed by MTT assay. Briefly, cells were seeded in 96-well plates (2000 - 3000 cells/plate). After $24 \mathrm{~h}$ incubation, the cells were treated with various concentrations of compounds. After treatment for $72 \mathrm{~h}$, a volume of $20 \mu \mathrm{L}$ of MTT solution $(5 \mathrm{mg} / \mathrm{mL})$ was added to each well and incubated for additional $2-4 \mathrm{~h}$ incubation at $37{ }^{\circ} \mathrm{C}$. Then the medium was discarded, and the formazan salt was dissolved with $150 \mathrm{~mL}$ DMSO for 15 - 20 minutes. The absorbance of each well was measured at $570 \mathrm{~nm}$ using a Spectra MAX M5 microplate spectrophotometer (Molecular Devices, CA, USA), and the median inhibitory concentration ( $\left.\mathrm{IC}_{50}\right)$ values were calculated. Three replicate wells were used for each analysis. The results were obtained from three separate experiments.

\subsubsection{Colony Formation Assay}

To test the survival of cells treated with compound 35, HCT116 cells (500 cells/well) were plated in a 6-well plate and incubated overnight at $37^{\circ} \mathrm{C}$, followed by various concentrations of 35 treatment $(0-5.0 \mu \mathrm{M})$ for 15 days with fresh medium. Finally, the cells were washed with cold 
phosphate-buffered saline (PBS) for twice. Colonies were fixed with $4 \%$ paraformaldehyde and stained with a $0.5 \%$ crystal violet solution for 15 minutes, and the colonies ( $>50$ cells) were counted under microscope. The data are expressed from three independent experiments. The number of colonies in treated cultures was expressed as a percentage of the control cultures.

\subsubsection{Flow Cytometry}

The cell cycle distribution of SW620 cells after $24 \mathrm{~h}$ exposure to various concentrations of $\mathbf{3 5}$ was monitored by flow cytometric analysis using a FACScan flow cytometer (Becton Dickinson USA). Briefly, SW620 cells $\left(2 \times 10^{5}\right.$ cells/well) were seeded in 6-well plates and incubated overnight at $37^{\circ} \mathrm{C}$. After $24 \mathrm{~h}$ treatment, the cells were harvested and washed with cold PBS twice, and fixed with $75 \%$ alcohol at $4{ }^{\circ} \mathrm{C}$. $24 \mathrm{~h}$ later, cells were stained with propidium iodide (PI) and analyzed by flow cytometry. Then data were analyzed with FlowJo software.

\subsubsection{Apoptotic Assay}

To further confirm the apoptosis inducing effect of compound 35, Annexin V-FITC apoptosis detection kit was used. HCT116 cells $\left(2 \times 10^{5}\right.$ cells/well $)$ were seeded in 6-well plates and incubated overnight at $37{ }^{\circ} \mathrm{C}$. After $24 \mathrm{~h}$ exposure to various concentrations of 35, cells were harvested and washed with cold PBS twice. After centrifugation, cells were stained with Annexin V-FITC and PI, and then analyzed with FCM (Becton- Dickinson, USA). Then data were analyzed with FlowJo software.

\subsubsection{Wound-healing migration assay}

The inhibition of tumor cell migration by compound $\mathbf{3 5}$ was determined by wound-healing migration assay. MCF-7 cells were seeded onto 6-well plates, when grew to $80-90 \%$ confluence and then the "wound" were scraped by a $0.1 \mathrm{~mL}$ sterile pipette tips. Fresh medium containing $10 \%$ fetal bovine serum and different concentrations of $\mathbf{3 5}$ were added. Cells were photographed after 0 , $12,24 \mathrm{~h}$ incubation at $37^{\circ} \mathrm{C}$, respectively.

\subsubsection{Mice and tumor model}

All animal experiments were approved and conducted by the Institutional Animal Care and Treatment Committee of Sichuan University in China. $100 \mathrm{~mL}$ tumor cell (HCT116) suspension containing $1 \times 10^{7}$ cells were injected subcutaneously into the right flank of the seven-week-old female $\mathrm{BALB} / \mathrm{c}$ athymic nude mice. After one week, when average tumor volume reached approximately $100 \mathrm{~mm}^{3}$, mice were separated into three groups randomly ( 8 mice per group), and received intraperitoneally injection (i.p.) of $\mathbf{3 5}$ at dose of $40 \mathrm{mg} / \mathrm{kg}, 80 \mathrm{mg} / \mathrm{kg}$ or vehicle, respectively once two days for 24 days. Tumor growth and body weight were measured every two days during the treatment. The tumor volumes were calculated according to the formula as follow: volume $\left(\mathrm{mm}^{3}\right)=\left(\mathrm{L} \times \mathrm{W}^{2}\right) \times 0.5$, where $\mathrm{L}$ is the length and $\mathrm{W}$ is the width. Growth inhibition was calculated from the start of treatment by comparison of the mean change in tumor volume for vehicle and treated group as before. 


\section{Acknowledgements}

The authors are grateful for the support from the National Science Foundation of China (81472780) and the National Key Program of China (2012ZX09103101-022).

\section{Reference}

[1] L.A. Torre, F. Bray, R.L. Siegel, J. Ferlay, J. Lortet-Tieulent, A. Jemal, Global cancer statistics, 2012, CA: a cancer journal for clinicians, 65 (2015) 87-108.

[2] P. Guo, Z.L. Huang, P. Yu, K. Li, Trends in cancer mortality in China: an update, Annals of oncology : official journal of the European Society for Medical Oncology / ESMO, 23 (2012) 2755-2762.

[3] B. Meunier, Hybrid molecules with a dual mode of action: dream or reality?, Accounts of chemical research, 41 (2008) 69-77.

[4] D. Havrylyuk, B. Zimenkovsky, O. Vasylenko, A. Gzella, R. Lesyk, Synthesis of new 4-thiazolidinone-, pyrazoline-, and isatin-based conjugates with promising antitumor activity, J Med Chem, 55 (2012) 8630-8641.

[5] S. Lee, K. Sivakumar, W.S. Shin, F. Xie, Q. Wang, Synthesis and anti-angiogenesis activity of coumarin derivatives, Bioorganic \& medicinal chemistry letters, 16 (2006) 4596-4599.

[6] X.H. Liu, H.F. Liu, J. Chen, Y. Yang, B.A. Song, L.S. Bai, J.X. Liu, H.L. Zhu, X.B. Qi, Synthesis and molecular docking study of novel coumarin derivatives containing 4,5-dihydropyrazole moiety as potential antitumor agents, Bioorganic \& medicinal chemistry letters, 20 (2010) 5705-5708.

[7] W. Zhang, Z. Li, M. Zhou, F. Wu, X. Hou, H. Luo, H. Liu, X. Han, G. Yan, Z. Ding, R. Li, Synthesis and biological evaluation of 4-(1,2,3-triazol-1-yl)coumarin derivatives as potential antitumor agents, Bioorganic \& medicinal chemistry letters, 24 (2014) 799-807.

[8] M.A. Musa, J.S. Cooperwood, M.O.F. Khan, A Review of Coumarin Derivatives in Pharmacotherapy of Breast Cancer, Current medicinal chemistry, 15 (2008) 2664-2679.

[9] S.S. Bhattacharyya, S. Paul, S.K. Mandal, A. Banerjee, N. Boujedaini, A.R. Khuda-Bukhsh, A synthetic coumarin (4-Methyl-7 hydroxy coumarin) has anti-cancer potentials against DMBA-induced skin cancer in mice, European Journal of Pharmacology, 614 (2009) 128-136.

[10] M.A. Musa, J.S. Cooperwood, M.O. Khan, A review of coumarin derivatives in pharmacotherapy of breast cancer, Current medicinal chemistry, 15 (2008) 2664-2679.

[11] A. Lacy, R. O'Kennedy, Studies on coumarins and coumarin-related compounds to determine their therapeutic role in the treatment of cancer, Current pharmaceutical design, 10 (2004) 3797-3811.

[12] M. Baba, Y.R. Jin, A. Mizuno, H. Suzuki, Y. Okada, N. Takasuka, H. Tokuda, H. Nishino, T. Okuyama, Studies on cancer chemoprevention by traditional folk medicines XXIV. Inhibitory effect of a coumarin derivative, 7-isopentenyloxycoumarin, against tumor-promotion, Biological \& Pharmaceutical Bulletin, 25 (2002) 244-246.

[13] N.E.B. Saidu, S. Valente, E. Bana, G. Kirsch, D. Bagrel, M. Montenarh, Coumarin polysulfides inhibit cell growth and induce apoptosis in HCT116 colon cancer cells, Bioorganic \& Medicinal Chemistry, 20 (2012) 1584-1593.

[14] M.A. Musa, V.L.D. Badisa, L.M. Latinwo, T.A. Patterson, M.A. Owens, Coumarin-based Benzopyranone Derivatives Induced Apoptosis in Human Lung (A549) Cancer Cells, Anticancer Research, 32 (2012) 4271-4276.

[15] S.M. Maira, F. Stauffer, J. Brueggen, P. Furet, C. Schnell, C. Fritsch, S. Brachmann, P. Chene, A. 
De Pover, K. Schoemaker, D. Fabbro, D. Gabriel, M. Simonen, L. Murphy, P. Finan, W. Sellers, C. Garcia-Echeverria, Identification and characterization of NVP-BEZ235, a new orally available dual phosphatidylinositol 3-kinase/mammalian target of rapamycin inhibitor with potent in vivo antitumor activity, Molecular cancer therapeutics, 7 (2008) 1851-1863.

[16] M.A. Dawson, R.K. Prinjha, A. Dittmann, G. Giotopoulos, M. Bantscheff, W.I. Chan, S.C. Robson, C.W. Chung, C. Hopf, M.M. Savitski, C. Huthmacher, E. Gudgin, D. Lugo, S. Beinke, T.D. Chapman, E.J. Roberts, P.E. Soden, K.R. Auger, O. Mirguet, K. Doehner, R. Delwel, A.K. Burnett, P. Jeffrey, G. Drewes, K. Lee, B.J. Huntly, T. Kouzarides, Inhibition of BET recruitment to chromatin as an effective treatment for MLL-fusion leukaemia, Nature, 478 (2011) 529-533.

[17] C.A. Bernhart, P.M. Perreaut, B.P. Ferrari, Y.A. Muneaux, J.L. Assens, J. Clement, F. Haudricourt, C.F. Muneaux, J.E. Taillades, M.A. Vignal, et al., A new series of imidazolones: highly specific and potent nonpeptide AT1 angiotensin II receptor antagonists, J Med Chem, 36 (1993) 3371-3380.

[18] S.N. Mokale, D. Lokwani, D.B. Shinde, Synthesis, biological activity and docking study of imidazol-5-one as novel non-nucleoside HIV-1 reverse transcriptase inhibitors, Bioorg Med Chem, 20 (2012) 3119-3127.

[19] A.A. Adjei, R.B. Cohen, W. Franklin, C. Morris, D. Wilson, J.R. Molina, L.J. Hanson, L. Gore, L. Chow, S. Leong, L. Maloney, G. Gordon, H. Simmons, A. Marlow, K. Litwiler, S. Brown, G. Poch, K. Kane, J. Haney, S.G. Eckhardt, Phase I pharmacokinetic and pharmacodynamic study of the oral, small-molecule mitogen-activated protein kinase kinase 1/2 inhibitor AZD6244 (ARRY-142886) in patients with advanced cancers, Journal of clinical oncology : official journal of the American Society of Clinical Oncology, 26 (2008) 2139-2146.

[20] D.A. Altomare, L.L. Zhang, J. Deng, A. Di Cristofano, A.J. Klein-Szanto, R. Kumar, J.R. Testa, GSK690693 Delays Tumor Onset and Progression in Genetically Defined Mouse Models Expressing Activated Akt, Clinical Cancer Research, 16 (2010) 486-496.

[21] El-Nassan, H. B., Recent progress in the identification of BRAF inhibitors as anti-cancer agents. European journal of medicinal chemistry, 72(2014) 170-205.

[22] M. Classen, H.G. Dammann, W. Domschke, K.J. Hengels, W. Huttemann, W. Londong, M. Rehner, B. Simon, L. Witzel, J. Berger, Short-Duration Treatment of Duodenal-Ulcer with Omeprazole and Ranitidine - Results of a Multi-Centre Trial in Germany, Deut Med Wochenschr, 110 (1985) 210-215. [23] Y.F. Li, G.F. Wang, P.L. He, W.G. Huang, F.H. Zhu, H.Y. Gao, W. Tang, Y. Luo, C.L. Feng, L.P. Shi, Y.D. Ren, W. Lu, J.P. Zuo, Synthesis and anti-hepatitis B virus activity of novel benzimidazole derivatives, Journal of Medicinal Chemistry, 49 (2006) 4790-4794.

[24] K.Y. Chang, S.Y. Tsai, C.M. Wu, C.J. Yen, B.F. Chuang, J.Y. Chang, Novel Phosphoinositide 3-Kinase/mTOR Dual Inhibitor, NVP-BGT226, Displays Potent Growth-Inhibitory Activity against Human Head and Neck Cancer Cells In Vitro and In Vivo, Clinical Cancer Research, 17 (2011) 7116-7126.

[25] M.A. Dawson, R. Prinjha, A. Dittman, G. Giotopoulos, M. Bantscheff, W.I. Chan, S. Robson, C.W. Chung, C. Hopf, M. Savitski, K. Dohner, A.K. Burnett, R. Delwel, H. Carola, E. Gudgin, D. Lugo, S. Beinke, P. Soden, K.R. Auger, O. Mirguet, P. Jeffrey, G. Drewes, K. Lee, T. Kouzarides, B.J.P. Huntly, Inhibition of BET Recruitment to Chromatin As An Effective Treatment for MLL-Fusion Leukaemia, Blood, 118 (2011) 27-28.

[26] C.H. Huang, D. Mandelker, O. Schmidt-Kittler, Y. Samuels, V.E. Velculescu, K.W. Kinzler, B. Vogelstein, S.B. Gabelli, L.M. Amzel, The structure of a human p110 alpha/p85 alpha complex elucidates the effects of oncogenic PI3K alpha mutations, Science, 318 (2007) 1744-1748. 
Fig. 1. A few of benzimidazole and imidazoquinoline derivatives with antitumor activities.

Fig. 2. The effect of compound 35 on cancer cells viability (A) Proliferation of HCT116, MCF-7, SW620, CT26, A549 and LO2 cells treated with various concentrations $(0-20 \mu \mathrm{M})$ of 35 and Cisplatin for $72 \mathrm{~h}$, respectively. Cell viability was detected by MTT assay. The data are expressed as the means $\pm \mathrm{SD}$ from three independent experiments. (B) and (C) The colony clusters were detected after a 20-day 35 treatment. Quantification is shown in the right panels. Images shown are representatives of three independent experiments. $(* * p<0.01)$.

Fig. 3. Compound 35 induced G0/G1 cell-cycle arrest and apoptosis of SW620 cells. (A) SW620 cells were treated with various concentrations of $35(0,0.3125,0.625,1.25,5.0 \mu \mathrm{M})$ for $24 \mathrm{~h}$. (B) SW620 cells were exposed to 35 at indicated doses for $24 \mathrm{~h}$, and the level of apoptosis was evaluated using the Annexin V/PI dual-labeling technique, and analyzed by flow cytometry. Data shown are representative of three independent experiments.

Fig. 4. Compound 35 inhibited breast cancer cell MCF-7 migration in vitro.

Fig. 5. Effects of compound 35 on the growth of xenografts in nude mice in vivo. (A) HCT116 tumor-bearing nude mice were treated as described with vehicle, 35 at 40 and $80 \mathrm{mg} / \mathrm{kg}$, the mean tumor volumes \pm SD of five mice per every group. (B) After the tumor cell inoculation, the body weight of the 35 treatment and vehicle groups were counted, and there were no significant difference among the groups. 
684 685<smiles>[R]c1ccc2oc(=O)c3[nH]c(=O)n([R1])c3c2c1</smiles>

$$
\mathrm{IC}_{50}(\mu \mathrm{M})^{a}
$$

\begin{tabular}{|c|c|c|c|c|c|}
\hline \multirow{2}{*}{ Compd. } & \multirow{2}{*}{$\mathrm{R}^{1}$} & \multirow{2}{*}{$\mathrm{R}^{2}$} & \multirow[b]{2}{*}{ U87-MG } & \multirow[b]{2}{*}{ PC-3 } & \multirow[b]{2}{*}{ HCT116 } \\
\hline & & & & & \\
\hline 9 & $\mathrm{C}_{6} \mathrm{H}_{5}$ & $\mathrm{C}_{6} \mathrm{H}_{5}$ & $>40$ & $>40$ & - \\
\hline 10 & $\mathrm{C}_{6} \mathrm{H}_{5}$ & pyridin-3-yl & $>40$ & $>40$ & - \\
\hline 11 & $\mathrm{C}_{6} \mathrm{H}_{5}$ & $\mathrm{C} 3-\mathrm{NH}_{2}-\mathrm{C}_{6} \mathrm{H}_{4}$ & $>40$ & $>40$ & - \\
\hline 12 & $\mathrm{C}_{6} \mathrm{H}_{5}$ & 2-Me- $\mathrm{C}_{6} \mathrm{H}_{4}$ & $>40$ & - & - \\
\hline 13 & $\mathrm{C}_{6} \mathrm{H}_{5}$ & $4-\mathrm{OH}-\mathrm{C}_{6} \mathrm{H}_{4}$ & $>40$ & - & - \\
\hline 14 & $\mathrm{C}_{6} \mathrm{H}_{5}$ & & $>40$ & $>40$ & $>40$ \\
\hline
\end{tabular}

15

$\mathrm{C}_{6} \mathrm{H}_{5} \quad$ pyridin-4-yl $\quad 38.74 \pm 1.64$

16

$\mathrm{C}_{6} \mathrm{H}_{5}$

quinolin-3-yl

$35.6 \pm 2.87$

$34.05 \pm 3.43$

$31.5 \pm 4.89$

17

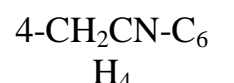

2-Me- $\mathrm{C}_{6} \mathrm{H}_{4}$

$>40$

$>40$

$>40$

18
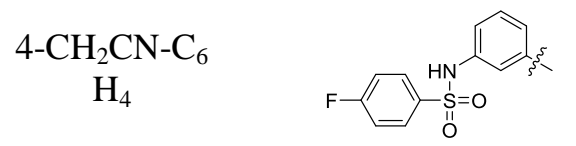

$>40$

$>40$

$>40$

19

$$
\begin{gathered}
\text { 4- } \mathrm{CH}_{2} \mathrm{CN}-\mathrm{C}_{6} \\
\mathrm{H}_{4}
\end{gathered}
$$

$3-\mathrm{NH}_{2}-\mathrm{C}_{6} \mathrm{H}_{4}$

$>40$

$36.51 \pm 3.32$ 


\begin{tabular}{|c|c|c|c|c|c|}
\hline 20 & $\begin{array}{c}4-\mathrm{CH}_{2} \mathrm{CN}-\mathrm{C}_{6} \\
\mathrm{H}_{4}\end{array}$ & $\mathrm{C}_{6} \mathrm{H}_{5}$ & $31.42 \pm 5.46$ & $35.31 \pm 2.56$ & $>40$ \\
\hline 21 & $\begin{array}{c}4-\mathrm{CH}_{2} \mathrm{CN}-\mathrm{C}_{6} \\
\mathrm{H}_{4}\end{array}$ & 4-OH- $\mathrm{C}_{6} \mathrm{H}_{4}$ & $29.59 \pm 4.30$ & $30.59 \pm 3.21$ & $30.13 \pm 4.44$ \\
\hline 22 & $\begin{array}{c}4-\mathrm{CH}_{2} \mathrm{CN}-\mathrm{C}_{6} \\
\mathrm{H}_{4}\end{array}$ & pyridin-3-yl & $>40$ & $>40$ & $29.37 \pm 5.56$ \\
\hline 23 & $\begin{array}{c}4-\mathrm{CH}_{2} \mathrm{CN}-\mathrm{C}_{6} \\
\mathrm{H}_{4}\end{array}$ & $\begin{array}{l}\text { 4-(methylsulfo } \\
\text { nyl)phenyl }\end{array}$ & $39.72 \pm 0.22$ & $29.61 \pm 2.32$ & - \\
\hline 24 & $\begin{array}{c}4-\mathrm{CH}_{2} \mathrm{CN}-\mathrm{C}_{6} \\
\mathrm{H}_{4}\end{array}$ & pyridin-4-yl & $36.42 \pm 1.45$ & $37.06 \pm 3.50$ & $37.2 \pm 2.10$ \\
\hline 25 & $\begin{array}{c}4-\mathrm{CH}_{2} \mathrm{CN}-\mathrm{C}_{6} \\
\mathrm{H}_{4}\end{array}$ & quinolin-3-yl & $34.9 \pm 2.40$ & $30.25 \pm 3.60$ & $28.40 \pm 2.60$ \\
\hline 26 & $4-\mathrm{OMe}-\mathrm{C}_{6} \mathrm{H}_{4}$ & pyridin-3-yl & $>40$ & $>40$ & $>40$ \\
\hline 27 & $4-\mathrm{OMe}-\mathrm{C}_{6} \mathrm{H}_{4}$ & pyridin-4-yl & $>40$ & $>40$ & $>40$ \\
\hline 28 & $4-\mathrm{OMe}-\mathrm{C}_{6} \mathrm{H}_{4}$ & quinolin-3-yl & $>40$ & $>40$ & $>40$ \\
\hline 29 & $2-\mathrm{Me}-\mathrm{C}_{6} \mathrm{H}_{4}$ & quinolin-3-yl & $>40$ & $>40$ & $>40$ \\
\hline 30 & $2-\mathrm{Me}-\mathrm{C}_{6} \mathrm{H}_{4}$ & pyridin-3-yl & $>40$ & $>40$ & $>40$ \\
\hline 31 & $2-\mathrm{Me}-\mathrm{C}_{6} \mathrm{H}_{4}$ & pyridin-4-yl & $>40$ & $>40$ & $>40$ \\
\hline 32 & $\begin{array}{c}4-\mathrm{C}\left(\mathrm{CH}_{3}\right)_{2}-\mathrm{C}_{6} \\
\mathrm{H}_{4}\end{array}$ & pyridin-3-yl & $25.62 \pm 3.80$ & $38.20 \pm 2.10$ & - \\
\hline 33 & $\begin{array}{c}4-\mathrm{C}\left(\mathrm{CH}_{3}\right)_{2}-\mathrm{C}_{6} \\
\mathrm{H}_{4}\end{array}$ & pyridin-4-yl & $28.55 \pm 2.30$ & $29.01 \pm 4.60$ & - \\
\hline 34 & $\begin{array}{c}4-\mathrm{C}\left(\mathrm{CH}_{3}\right)_{2}-\mathrm{C}_{6} \\
\mathrm{H}_{4}\end{array}$ & quinolin-3-yl & $33.42 \pm 2.50$ & $19.76 \pm 1.60$ & $20.40 \pm 3.60$ \\
\hline Cisplatin & - & - & $>20$ & $>20$ & 12.3 \\
\hline
\end{tabular}

$685{ }^{a}$ Inhibitory activity was assayed by exposure for $72 \mathrm{~h}$ to substances and expressed as 686 concentration required to inhibit tumor cell proliferation by $50 \%\left(\mathrm{IC}_{50}\right)$. SD, standard deviation (n $687=3)$. 
691

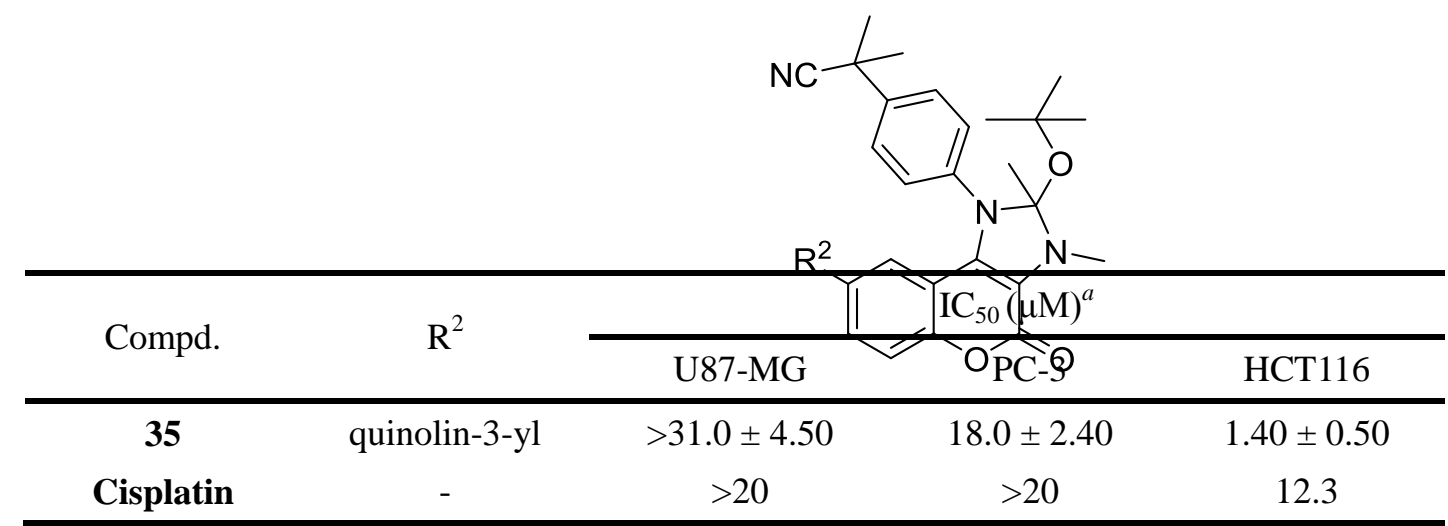

${ }^{a}$ Inhibitory activity was assayed by exposure for $72 \mathrm{~h}$ to substances and expressed as concentration required to inhibit tumor cell proliferation by $50 \%\left(\mathrm{IC}_{50}\right)$. SD, standard deviation (n $=3)$.

\section{Schemes}<smiles>CC#CCC(C)C1CC1CCCC</smiles>

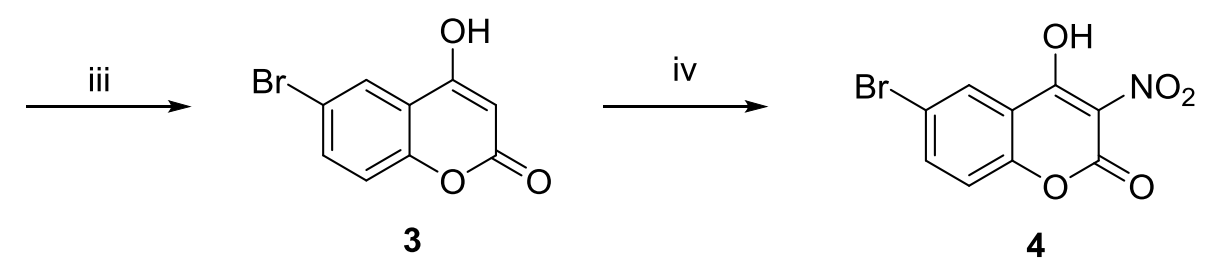

Scheme 1. Reagents and conditions: (i) acetic anhydride, pyridine, $100{ }^{\circ} \mathrm{C}, 3.5 \mathrm{~h}, 92 \%$; (ii) $\mathrm{AlCl}_{3}$, $701150{ }^{\circ} \mathrm{C}, 3.5 \mathrm{~h}, 72 \%$; (iii) diethyl carbonate, $\mathrm{NaH}$, Toluene, $100{ }^{\circ} \mathrm{C}, 4 \mathrm{~h}, 71 \%$; (iv) $\mathrm{HNO}_{3}, \mathrm{DCM}$, 702 $0{ }^{\circ} \mathrm{C}, 2 \mathrm{~h}, 94 \%$; (v) $\mathrm{POCl}_{3}, \mathrm{Et}_{3} \mathrm{~N}$, reflux, 1 h, $87 \%$. 
<smiles>[R]NC(C)(C)C(=O)c1c(Cl)c2cc(Br)ccc2oc1=O</smiles>

5<smiles>[R]Nc1c([N+](=O)[O-])c(=O)oc2ccc(Br)cc12</smiles>

$6 a-6 e$

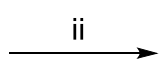<smiles>[R1]Nc1c(N)c(=O)oc2ccc(Br)cc12</smiles>

$7 a-7 g$<smiles>[R2]B(O)O</smiles>

$8 a-8 e$<smiles>[R]c1ccc2oc(=O)c3[nH]c(=O)n([R])c3c2c1</smiles>

9 - 34
704

$$
\begin{aligned}
\mathbf{a} & =\mathrm{C}_{6} \mathrm{H}_{5} \\
\mathbf{b} & =4-\mathrm{CH}_{2} \mathrm{CN}-\mathrm{C}_{6} \mathrm{H}_{4} \\
\mathrm{R}^{1}=\quad & \mathbf{c}=4-\mathrm{OMe}-\mathrm{C}_{6} \mathrm{H}_{4} \\
\mathbf{d} & =2-\mathrm{Me}-\mathrm{C}_{6} \mathrm{H}_{4} \\
\mathbf{e} & =4-\mathrm{C}\left(\mathrm{CH}_{3}\right)_{2} \mathrm{CN}-\mathrm{C}_{6} \mathrm{H}_{4}
\end{aligned}
$$

705

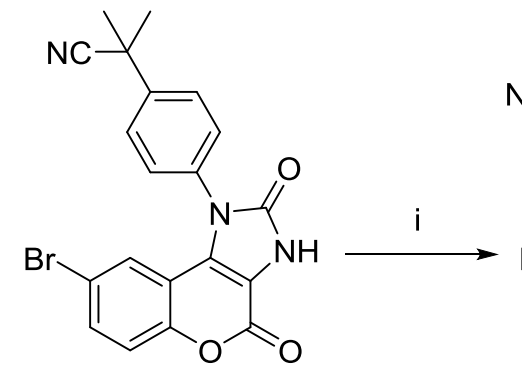

8

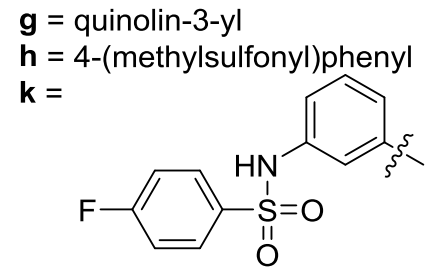

Scheme 2. Reagents and conditions: (i) DMF, r.t., $2 \mathrm{~h}, 93-97 \%$; (ii) $\mathrm{Fe}$, ethanol, $75 \%$, $\mathrm{NH}_{4} \mathrm{Cl}$, r.t., 4-5 h, 52-63 \%; (iii) CDI, $\mathrm{CH}_{3} \mathrm{COOH}, 2 \mathrm{~h}, 100{ }^{\circ} \mathrm{C}$, 45-74\%; (iv) $\mathrm{K}_{2} \mathrm{CO}_{3}, \mathrm{PdCl}_{2}$ (dppf) $\mathrm{CH}_{2} \mathrm{Cl}_{2}$, 1,4-dioxane : $\mathrm{H}_{2} \mathrm{O}=3: 1,65^{\circ} \mathrm{C}, 4-5 \mathrm{~h}, 40-60 \%$.<smiles>CC#CCN1c2c(c3cc(Br)ccc3oc2=O)N(c2ccc(C(C)(C)C#N)cc2)C1(C)OC(C)(C)C</smiles>

$35 a$<smiles>CN1c2c(c3cc(-c4cnc5ccccc5c4)ccc3oc2=O)N(c2ccc(C(C)(C)C#N)cc2)C1(C)OC(C)(C)C</smiles>

35

Scheme 3. Reagents and conditions: (i) $\mathrm{CH}_{3} \mathrm{I}$, Potassium tert-butanolate, DCM, $0{ }^{\circ} \mathrm{C}, 1 \mathrm{~h}, 7 \%$; (ii) $\mathrm{K}_{2} \mathrm{CO}_{3},\left[\mathrm{PdCl}_{2}\right.$ (dppf)] $\mathrm{CH}_{2} \mathrm{Cl}_{2}, 1$,4-dioxane : $\mathrm{H}_{2} \mathrm{O}=3: 1,65^{\circ} \mathrm{C}, 4-5 \mathrm{~h}, 55 \%$. 


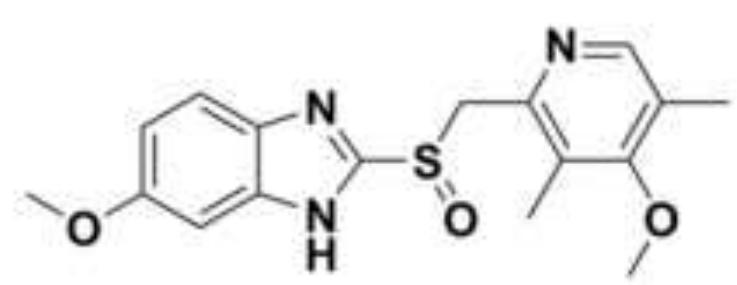

Omeprazole

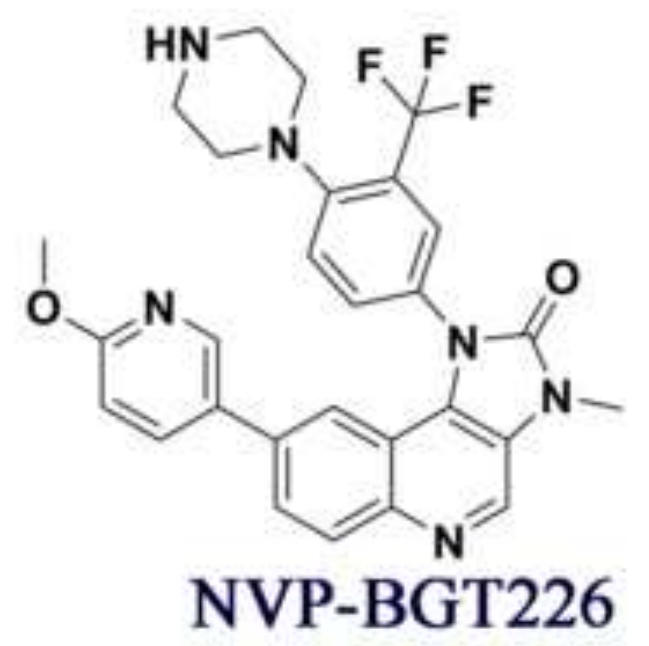

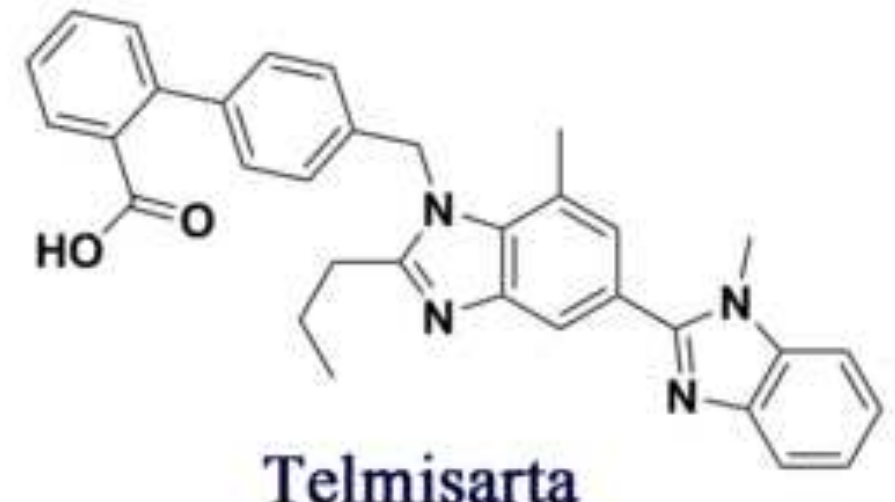

Telmisarta

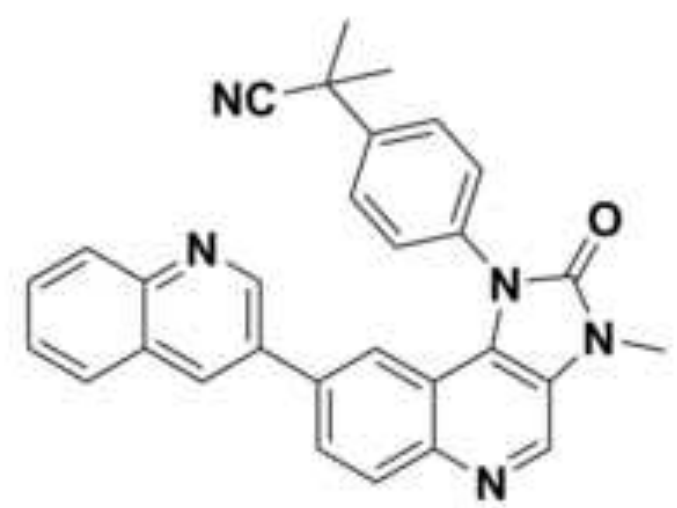

NVP-BEZ235

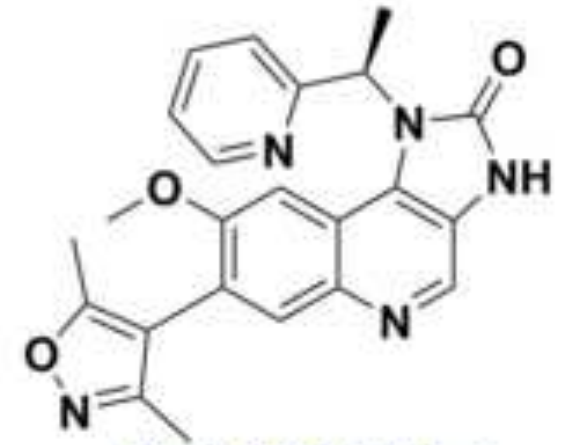

Gsk121051A 
A

\begin{tabular}{lllllll} 
& \multicolumn{5}{c}{$\mathrm{IC}_{\text {so }}(\mu \mathrm{M})$} \\
\cline { 2 - 6 } & HCT116 & MCF-7 & SW620 & CT26 & A549 & LO2 \\
\hline 35 & $1.40 \pm 0.5$ & $1.70 \pm 0.3$ & $3.55 \pm 1.3$ & $3.50 \pm 0.7$ & $9.50 \pm 1.8$ & $37.0 \pm 5.3$
\end{tabular}

$\begin{array}{lllllll}\text { Cisplatin } & 12.30 \pm 2.9 & 4.50 \pm 1.8 & 12.40 \pm 2.6 & 15.10 \pm 3.6 & 9.97 \pm 2.1 & >20\end{array}$

B
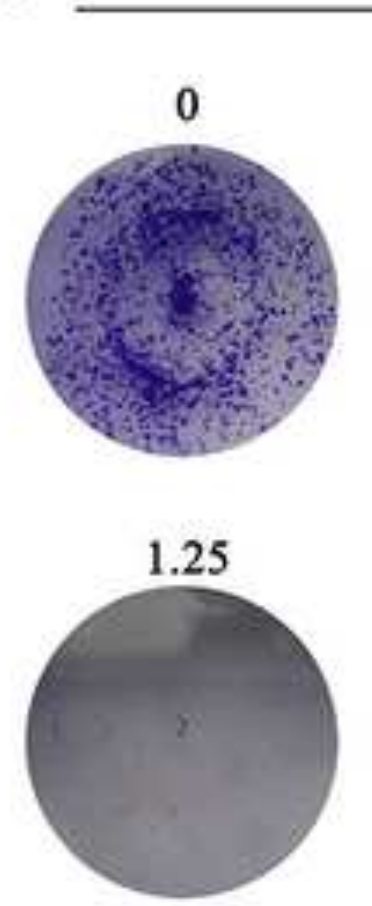

Compound $35(\mu \mathrm{M})$

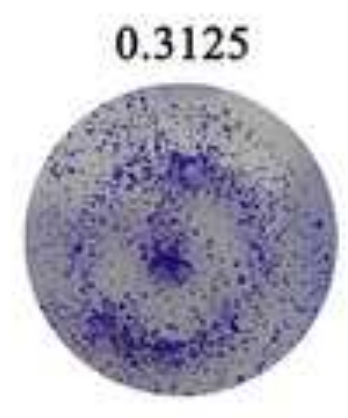

2.50

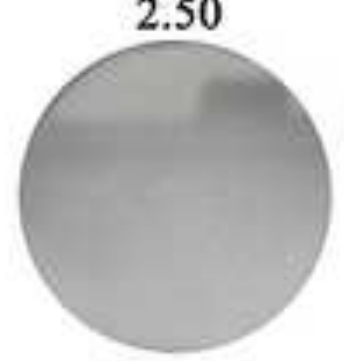

C

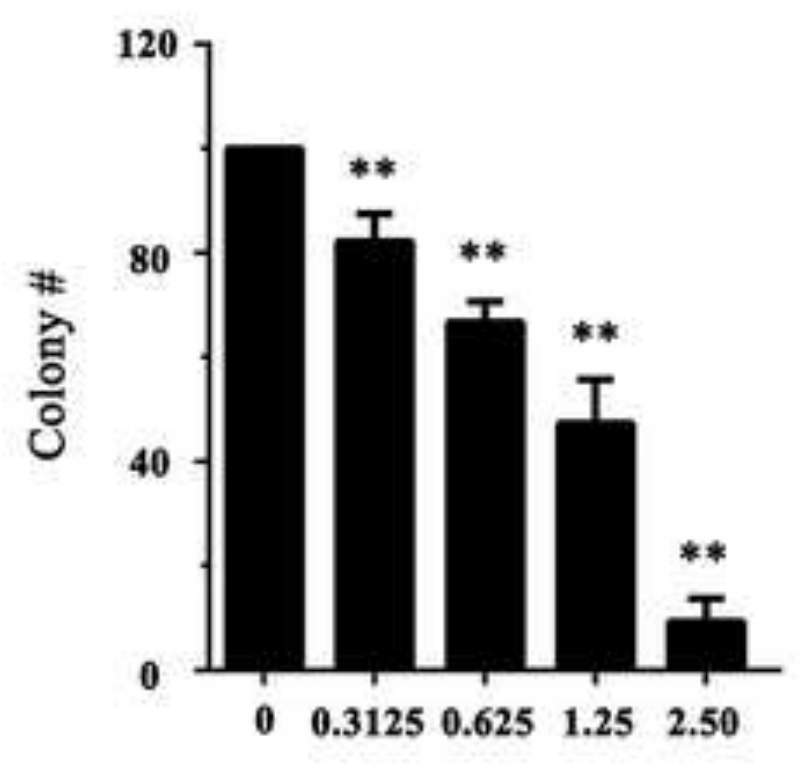

Compound $35(\mu \mathrm{M})$ 
A

Compound $35(\mu \mathrm{M})$

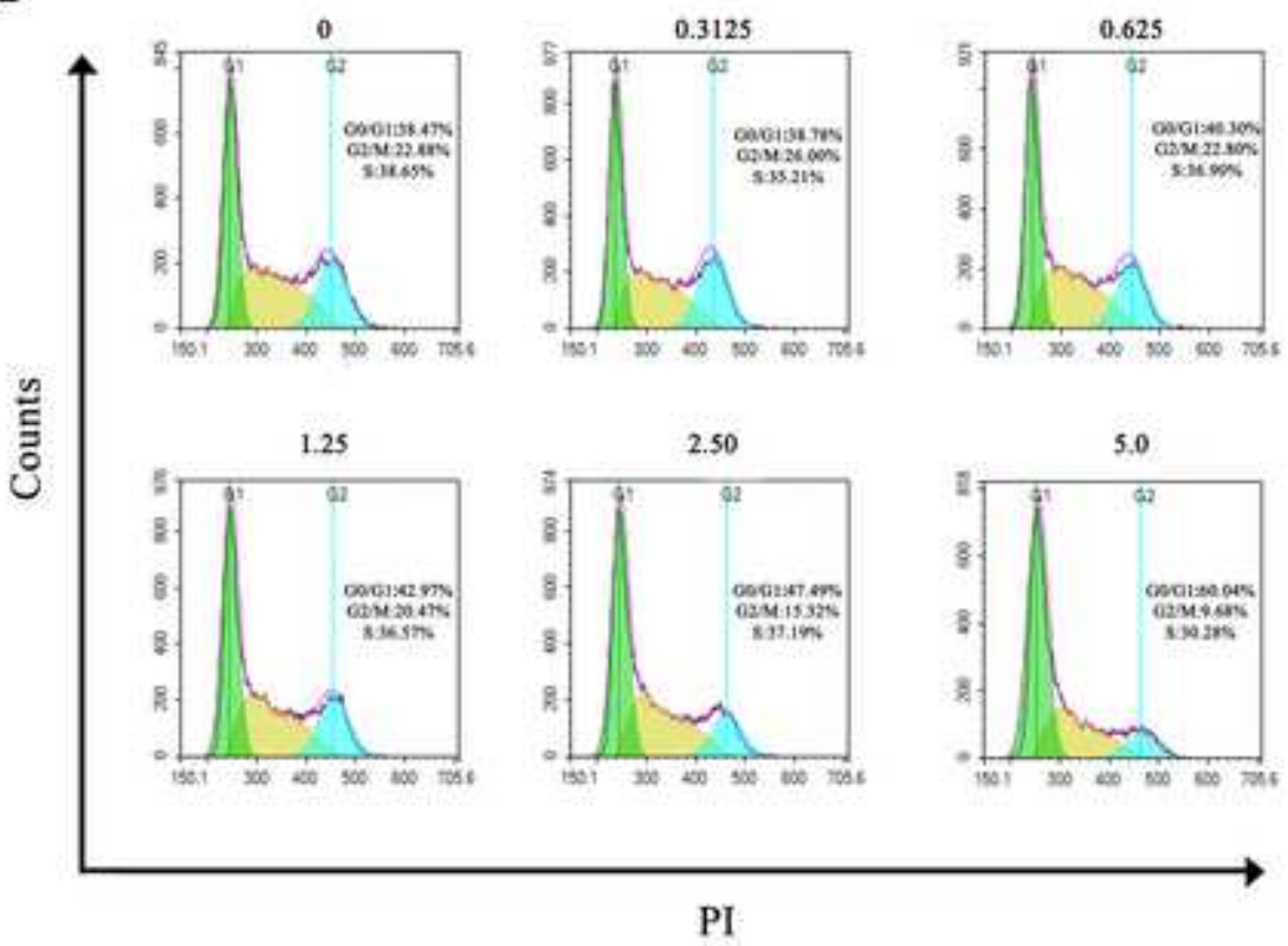

B

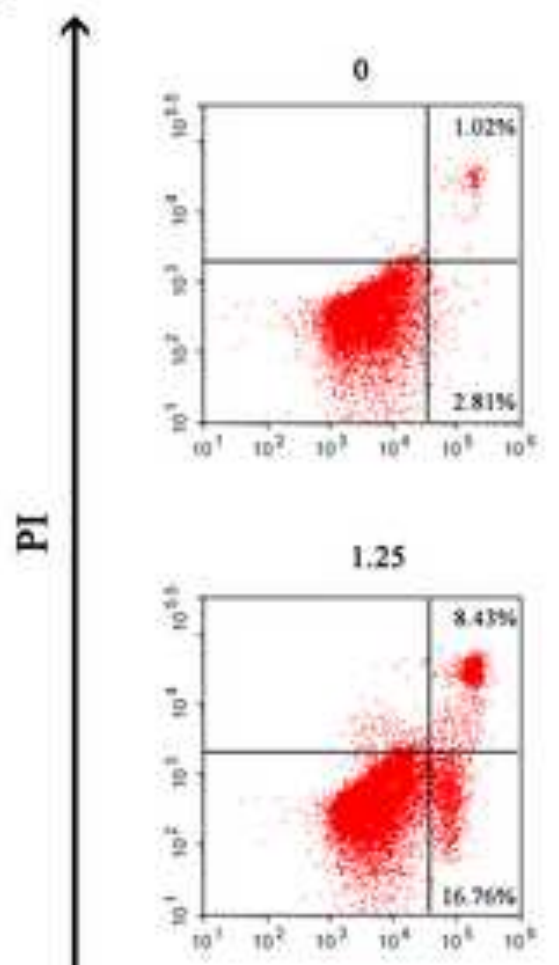

Compound $35(\mu \mathrm{M})$
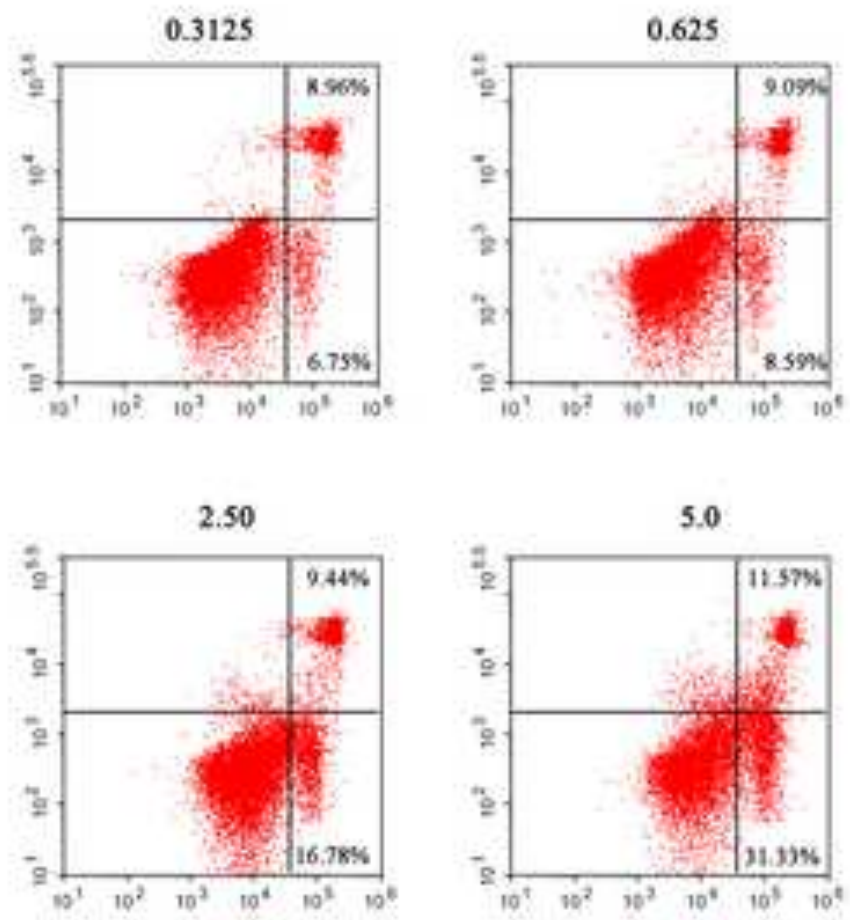

Annexin V 
Compound $35(\mu \mathrm{M})$
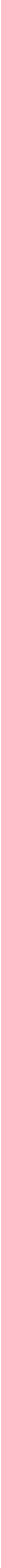

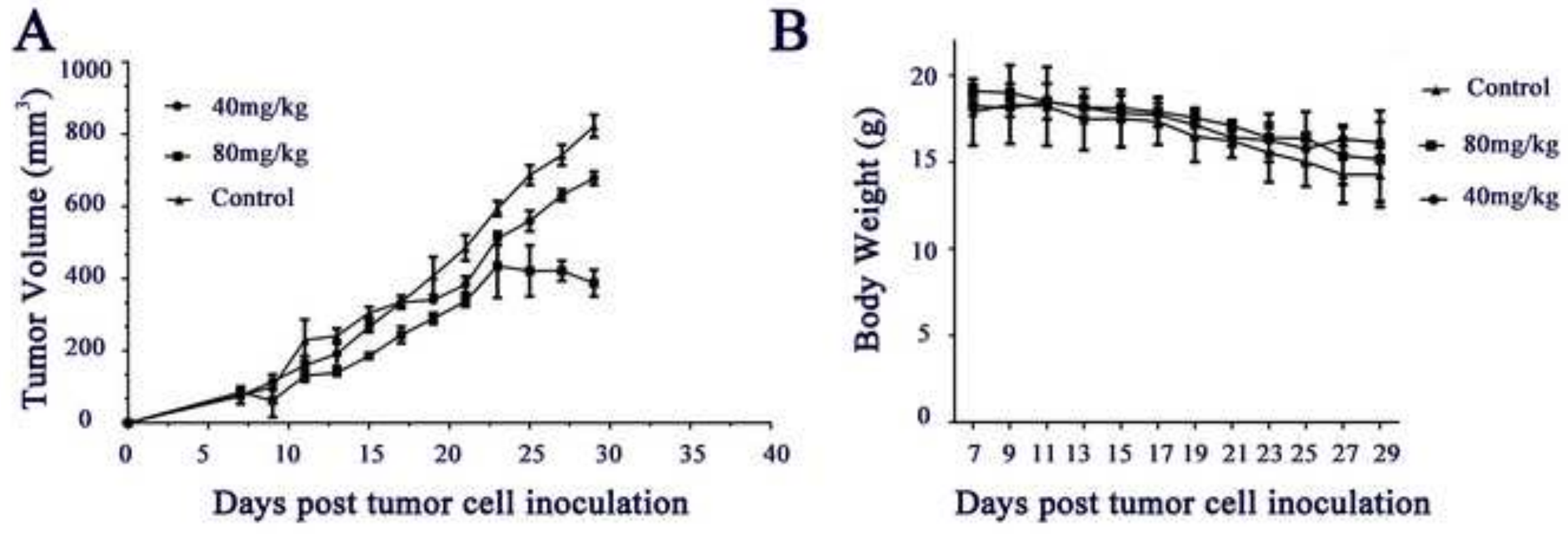


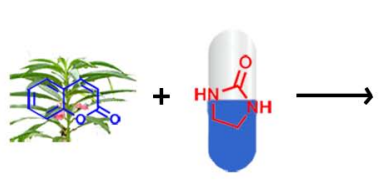

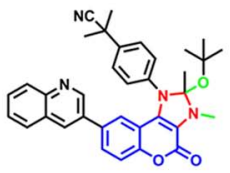

Compound 35

HCT116 IC I $_{50}=1.40 \mu \mathrm{M}$ MCF7 IC IC $_{50}=1.70 \mu \mathrm{M}$

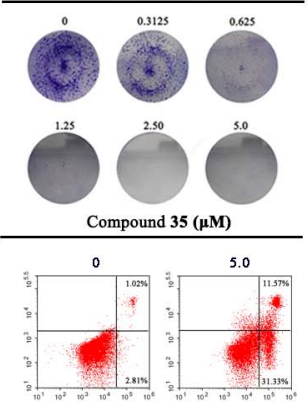

